Running head: CONTROL REVIEW

Control at Work: An Integrative, Lifespan-Informed Review

\author{
Rachel S. Rauvola ${ }^{1}$ \\ Cort W. Rudolph ${ }^{2}$ \\ ${ }^{1}$ DePaul University \\ ${ }^{2}$ Saint Louis University
}

\begin{abstract}
Author Note
Rachel S. Rauvola, Department of Psychology, DePaul University, Chicago, IL, USA. Cort W. Rudolph, Department of Psychology, Saint Louis University, St. Louis, MO, USA.

Correspondence concerning this article should be addressed to Rachel S. Rauvola, DePaul University, Byrne Hall, Chicago, IL, 60614, rrauvola@ depaul.edu, +1(314) 537-9837
\end{abstract}

The authors would like to acknowledge and thank Nicholas P. Carruth, Morgan E. Gleason, and Mackenzie M. Moreno for their assistance in the preparation of this work. Portions of this work are based on the first author's comprehensive examination completed at Saint Louis University. The authors would also like to thank Dustin K. Jundt and Candice L. Thomas for their helpful comments on an earlier version of this piece.

Please Cite As:

Rauvola, R. S., \& Rudolph, C. W. (2021). Control at work: An integrative, lifespan-informed review. Work, Aging and Retirement. [In Press Accepted Manuscript]. 


\begin{abstract}
Control is one of the most ubiquitous and fundamental concepts to the study of psychology, including to theory, research, and practice related to aging and work. Indeed, control constructs exist in many different forms (e.g., self-efficacy, job autonomy, locus of control), and they have been extensively linked to performance and well-being with age. This paper provides a review of age- and work-relevant theory and research pertaining to a variety of "actual," perceived, and enacted control constructs. The paper seeks to fulfill three goals. First, we review predominant control constructs with respect to theory and research, considering their distinguishing and overlapping features, relationships with age- and work-relevant concerns, and areas of consensus and ambiguity. Second, we synthesize and organize our review findings into a work-focused "lifespan control framework" to guide theoretical revision, hypothesis formation, and construct choice/comparisons, and we provide recommendations to researchers for using this framework. Third and finally, we generate a focused research agenda for impactful studies of age, control, and work. The concept of control has contributed to our knowledge of and practice with workrelevant processes, and this review aims to aid in integration, organization, and innovation to move the study of age, control, and work forward.
\end{abstract}

Keywords: control, lifespan development, job autonomy, locus of control, well-being 
Control at Work: An Integrative, Lifespan-Informed Review

Of all the concepts studied by psychologists throughout the history of the discipline, “control" and "development" are undoubtedly two of the most ubiquitous — and intertwined. Possessing, perceiving, wielding (and losing) control, in addition to the passage of time, the process of aging, and the coincidence of developmental changes and stability, are central to the human experience. At the person level, control can be defined as an individual's situational discretion, power, or influence over their actions, accompanied by the ability to successfully engage in chosen actions and/or to receive rewards or desired outcomes as a result of their choice and actions (see Table 1 and Figure 1, “1”). Such agency and influence are integral to our understanding of how individuals develop — that is, how they mature over time and experience positive and negative changes in adaptive capacity (Baltes, 1987). Control is distributed in diverse and impactful ways within organizations and across the lifespan. Jobs, organizations, and careers are hierarchically graded, and the human experience is largely defined by gains and losses in capacities in and across domains - and thereby by inevitable trade-offs in choice and action. Indeed, the study of aging and work is based in shared metaphors and fundamental assumptions about the nature of control and development: control is a prominent device for demarcating and defining age and aging, and development unfolds through control acquisition, perception, use, maintenance, and loss.

A great deal of literature has been dedicated to discussing and studying the role of control in bolstering performance and well-being across the lifespan (e.g., Chipperfield et al., 2017; Flammer, 1997; Heckhausen et al., 2019; Lachman, 2006; Lachman \& Firth, 2004; Lachman et al., 2011; Rodin, 1986). Control in a variety of forms defines and organizes relevant intra- and interpersonal differences (e.g., locus of control, self-efficacy, primary and secondary control 
striving), and intra- and inter-domain influences (e.g., autonomy at work: within one's job, work team; interplay between family and work control beliefs), that relate to individual functioning for aging workers. It thus provides a foundation for much of the theory, research, and practice that focuses on supporting workers across the lifespan. Various forms of control have been studied (and published) extensively in Work, Aging and Retirement in the past five years alone, considered alongside variables such as task performance (e.g., Müller et al., 2015), well-being (e.g., Liu et al., 2018), motivation (e.g., Shane et al., 2019), retirement planning (e.g., Heraty \& McCarthy, 2015), and workplace accommodations (e.g., Gignac et al., 2018). However, this literature lacks cohesion and direction, often providing little justification for where and why certain forms of control "matter" for key issues for aging workers. For example, there are important differences between each of the forms of control discussed in this review, and these differences must be systematically clarified and linked to core questions about aging and work to move the field forward.

More broadly, there is an apparent disconnect between conceptual, empirical, and pragmatic elements of the work and aging literature concerning control. Many recognize the fundamentality of control for understanding age and work, and control is commonly referenced and assessed in work and aging studies. Problematically, however, research remains limited in its engagement with control-related theories; selection and use of appropriate, clearly specified control constructs; and nuanced interpretations of findings to inform both revised theory and implementable practice. These gaps, though longstanding and pervasive, are not as wide as they may seem: indeed, many parallels and mutually informing concepts exist between the workplace control and aging literatures, and our review seeks to highlight those where maximal impact, but minimal theoretical "leaps," can be made. Aside from its fundamental areas of overlap with the 
study of aging and work, and the wealth of theory and forms of control available that researchers can consider, control is also one of the more "malleable," universal, and multifaceted aspects of work and life. This means that it lends itself well to a variety of possible interventions or levers for change, and it has wide-reaching, documented implications for motivation, well-being, and performance. The scope, range, and applicability of better understanding control as it relates to age and work, and particularly at a time when tensions between employee agency and empowerment and organizational control and automation are more salient than ever (e.g., Kellogg et al., 2020) especially among older workers (Alcover et al., 2021), make these topics critical to review and synthesize.

The present review seeks to accomplish three goals: 1) to review predominant control constructs with respect to both theory and research, considering their distinguishing and overlapping features, relationships with age- and work-relevant concerns, and areas of consensus and ambiguity; 2) to synthesize and organize review findings into a work-focused "lifespan control framework" that can guide theoretical revision as well as hypothesis formation and construct choice/comparisons; and 3) to generate a research agenda for future studies of age, control, and work. Given the wide scope of the control literature, our goal is not to summarize all research findings, nor to possibly discuss every area in which control has been explored with respect to age, work, and functioning (i.e., well-being and performance). Instead, we provide a lifespan-informed review of the concept of control, focused on work and functioning outcomes, that prioritizes breadth and synthesis. Thus, a balance of historical works and contemporary studies and perspectives will be provided, highlighting the diversity of thought in this literature and areas in need of theoretical and empirical attention. 
Following the structure implied by Figure 1, we begin with a discussion of broad control categories and definitions, followed by a detailed review of predominant constructs in each category that includes conceptual and practical definitions, theories, and models, and a sample of lifespan-relevant empirical evidence. Finally, we end with an integration of these concepts, presenting an organizing framework and recommendations for future research in this area of the literature.

It is important to note at the outset that control-related constructs-explicitly named, presumed, or predicated upon—are myriad, and thus only a selection of those most relevant and impactful to issues of age, aging, and work are considered in the present review. Other, less central constructs, such as causality orientation, learned helplessness, control as well-being, and predictability, are discussed elsewhere in the literature in various related reviews (e.g., Chanowitz \& Langer, 1980; Rodin, 1990; Skinner, 1996; Thompson \& Spacapan, 1991; see also Table 1, "1.4” and sub-constructs). Specifically, we focus on control constructs relevant to various key issues and pressing questions in the aging and work literature. We present these issues alongside the specific constructs from and with which we can learn the most to support aging workers (see Table 1).

\section{Control: Categories and Definitions}

Each control-related construct considered in this review falls within one of three categories: "actual" control, perceived control, and enacted control. "Actual" control refers to an objective level of available choices (i.e., among different "means" in goal striving; e.g., actions) and a) the ability to perform (i.e., availability of and ability to engage in particular means or methods successfully) or b) obtain a particular desired outcome as a result of these choices and performance (i.e., the translation of means or methods into desirable outcome(s) and avoidance 
of undesirable outcome(s)) in a given scenario (see Table 1 and Figure 1, "1.1"). Adopting Skinner's (1996) typology, "actual" control consists of agents-means relations (i.e., availability of goal-relevant means to individuals) and means-ends relations (i.e., the extent to which particular means or methods lead to desirable and undesirable outcomes). When discussing parallel perceived control constructs, Flammer (1997) uses the alternative terms "competence" and "contingency," respectively; this review uses both terms to facilitate comprehensiveness.

Although "actual" control theoretically exists, it must be inferred through personal (e.g., relevant demographics and resources, such as those related to age or socioeconomic status, that impact available goal-relevant means; Lachman, 1986; Mirowsky, 1995) or contextual attributes (e.g., job and organizational demands and resources, work designs, objective control opportunities; Haynes et al., 2009; Spector, 2002) that provide control (Skinner, 1996). "Actual” control is discussed as psychologically impactful for individuals if and when said individuals recognize this control (or lack thereof; Langer, 1979), and their control perceptions may or may not match the level of control they "actually" have (Lachman et al., 2011). For example, an individual who does not have access to goal-relevant means may still possess a belief in control over their situation and persist in goal striving, referred to as the illusion of control (Averill, 1973; Langer, 1975), and the opposite, wherein an individual who has goal-relevant means but does not perceive control may disengage (i.e., "learned helplessness"; see Table 1, "1.4.2”), occurs as well (Abramson et al., 1978; Roth, 1980; Seligman, 1975). Still, the presence or absence of "actual" control does exert structural limitations that cannot be discounted (Rauvola \& Rudolph, 2020).

Perceived control refers to individuals' beliefs about the availability of control, generally or in specific contexts (see Table 1 and Figure 1, “1.2”). As with "actual” control, our review 
considers perceived control as entailing competence or agents-means relations (e.g., expectancy, self-efficacy, types of autonomy and control) and contingency or means-ends relations (e.g., instrumentality, locus of control). The final category of control considered in this review is enacted control, which entails individuals' engagement in specific strategies (i.e., primary and secondary control mechanisms; e.g., Heckhausen et al., 2010) to self-regulate development and functioning across the lifespan (see Table 1 and Figure 1, “1.3”). Unlike the two forms of control discussed earlier, enacted control entails using control toward active, behavioral ends. Chanowitz and Langer (1980) describe this as "exercised control," and Lachman and colleagues (2011) place "strategy use" as a mediating behavioral and motivational factor in their model of control beliefs across the lifespan. Similarly, Flammer (1997) distinguishes "controlling” from control beliefs, describing this as the "actual regulation of a process" (p. 69), while Skinner (1996) writes of the importance of "experiences of control" (p. 551). Thus, although quite distinct from objective control and from perceptions of this control in and across contexts, enacted control serves as a behavioral mechanism by which individuals can act upon their perceived control (or lack thereof) in order to shape their environment and maximize functioning with age. Similar to "actual" and perceived control these strategies can be employed generally or in particular domains (e.g., the work context).

\section{Control Constructs, Theory, and Research}

A number of different control constructs fall within each of these broader control categories, and the lifespan-focused literature review provided next will focus on those of most relevance to the study of aging and work in particular. First, theory and research pertaining to “actual" and/or perceived control constructs will be reviewed, followed by a discussion of enacted control constructs. This literature review was conducted in the spirit of a "miner" review 
(Breslin \& Gatrell, 2020), drawing on existing research to identify and highlight conceptual gaps in our study of age, control, and work, reorganize and collectively categorize constructs and questions in the work-relevant control and lifespan literatures, and highlight areas where new connections can be made. In line with past conceptualizations of integrative reviews, we derived our definitions, questions, and insights from the review itself, rather than approaching the literature with preconceived notions and intended conclusions in mind (Elsbach \& van Knippenberg, 2020). However, we also sought to problematize through our review, identifying a broad but selective sample of theory and literature to consider, highlighting difference and plurality, and remaining reflexive about assumptions in the control literature (e.g., that control is invariably "good"; Alvesson \& Sandberg, 2020).

This approach shaped our review process and selection of age-, aging-, and lifespanoriented control studies to include in our discussion: specifically, we worked to identify and chart whence ideas about control, and their purported differences or similarities, emerged (e.g., theoretical origins and principles; conceptual and practical definitions) through in-depth reading of original manuscripts in each area of control. Based upon this, we conducted Google Scholar searches with relevant control keywords, author names, and/or theoretical model titles alongside age- and work-relevant keywords (e.g., "aging," "aging workers," “over time," “older workers," "lifespan"). In particular, we sought to identify both primary studies and existing review papers that provided not only a range of empirical findings but also discrepancies and ongoing debates.

We took a "snowball search" approach from here, identifying relevant citing papers (i.e., forward searches) and cited papers (i.e., backward searches) to read and distill into our summaries, critiques, recommendations, and identified applications. We did not set specific quotas for minimum or maximum numbers of papers reviewed for each construct or category, 
instead striving to maintain a general balance across our sections with coverage of similar topics in each area. Our review progressed recursively, progressing in the order presented in the following sections but with cycles of revision and re-envisioning based on the ongoing search and its emergent findings. Through this, we tried to access and depict the "core issues" of each control construct reviewed — both as they were intended and how they are (mis)applied — and how these inform age and work specifically.

\section{“Actual" and Perceived Control Constructs, Theory, and Research}

Given the interrelationships between "actual" and perceived control, as well as their cooccurrence and investigation in much of the literature, relevant constructs, theory, and research for these types of control will be discussed together. Still, both categories have identifiable and distinct overlaps with issues of age and work (see Table 1). Specifically, the category of "actual" control parallels with issues of physical and interpersonal aging processes (e.g., ageism, discrimination, changes in capacities and abilities) for the age-diverse workforce and population. Here, "actual" control applies a control lens to questions about how age-related biopsychosocial changes can both support and limit employees with respect to choices, performance, and outcomes in the work context. Similarly, perceived control can be related to how workers experience age, aging, and age-related changes, and how these experiences shape and relate to actual and believed competence and contingencies.

"Actual" and Perceived Agents-Means/Competence Constructs. The control constructs that fall within this category include expectancy, self-efficacy, and types of autonomy and control.

Expectancy: Conceptual and Practical Definitions. Perceived expectancy, which entails "a momentary belief concerning the likelihood that a particular act will be followed by a 
particular outcome" (Vroom, 1964, p. 17), has its origins in early motivation theory (e.g., Rotter, 1955; Tolman, 1934; Vroom, 1964) that sought to explain the direction of human behavior (see Table 1 and Figure 1, "1.2.1"). Motivation is fundamentally defined by control in this theoretical space, and perceived expectancy serves as a probability judgment regarding the translation of effort/action into a behavioral outcome (i.e., performance). Vroom's (1964) theoretical development of expectancy also integrates an external component of expectancy belief formation that should be borne in mind, suggesting that "outcomes attained by a person are dependent not only on the choices that he makes but also on events which are beyond his control" (p. 17). In this way, expectancy somewhat exists from an "actual" control perspective as well (see Table 1 and Figure 1, “1.1.1").

Expectancy: Theories and Models. In addition to being represented in early theories of (work) motivation by Vroom and others, perceived expectancy has also been adopted by or integrated with many theories relevant to work and lifespan functioning (see Table 1). This is perhaps unsurprising: as presented by Olson et al. (1996), all beliefs are "expectancies," and the concept of expectancy, which is comprised of a number of cognitive (e.g., other beliefs, past experience) and social influences, is the basis for all human behavior. Unlike many other control constructs discussed later, this fundamental role has led to generally consistent conceptualizations of expectancy across theories, save for Vroom's specified multiplicative motivational functions. For example, Weiner's attributional theory of achievement motivation and emotion (1985), and his earlier attribution theory (e.g., Weiner et al., 1971), builds the cognitive component of expectancy into a model with affect as well as additional control mechanisms (e.g., locus of control, outcome stability, and perceived controllability) in explaining motivated behavior. 
Additional well-known expectancy-value theories, or decisional choice theories (Kanfer, 1990), include Atkinson's (1957) theory of achievement motivation (positing that individual differences, expectancy, and perceived value of success influence motivation), Raynor's (1969) expansion of Atkinson's work to include goal systems and temporality, and Atkinson and Birch's (1970) dynamics of action theory, which treats motivated behavior patterns over time as a product of supporting and inhibiting forces (i.e., individual differences and situational factors) as well as expectancy and value. This class of theories assumes individuals are hedonistic in their decisions, maximizing positive and minimizing negative affect through striving toward high utility outcomes. This dovetails with lifespan theories, discussed later, which emphasize the maximization of gains and minimization of losses through enacted control in particular motivational and temporal contexts.

Again, perceived rather than "actual" expectancy takes center stage in these theories, but the presence of "actual" expectancy is hinted at through the inclusion of influential situation and person factors in many of these elaborations on Vroom's (1964) valence-instrumentalityexpectancy theory. Indeed, the somewhat divergent theory of planned behavior (Ajzen, 1991), and its predecessor, the theory of reasoned action (Fishbein \& Ajzen, 1975), contends that motivation to act is influenced by expectancies regarding one's ability to perform a given behavior, while also taking into account other attitudes and the social context (i.e., subjective norms and the expectations of others; see also Bartol, 1976; Mitchell \& Knudsen, 1973). Still, (perceived) expectancy is central to these theories, as is the desire of individuals to promote functioning, such as positive affect, well-being, and performance, over time. For detailed reviews of these theories and their applications to organizational behavior, readers can consult Kanfer (1990), Kanfer et al. (2017), and Pinder (2008). 
Expectancy: Age and Work-Relevant Empirical Evidence. With respect to the lifespan literature, expectancy primarily takes on a conceptual role in models of developmental selfregulation and enacted control, while other notable expectancy findings and issues have bearing on our study of key age and work issues as well. Broadly, expectancy applies to aging workers' competence judgments and motivated decision-making in context: specifically, expectancy relates to objective and subjective effort-performance probabilities within and across diverse, cross-domain goal systems, and this has implications for goal selection and striving (e.g., motivation to continue working; Kooij et al., 2008).

Objective (Rotter et al., 1954) and subjective expectancies have been studied in the motivation literature, with higher representation of the latter form. A meta-analysis by Van Eerde and Thierry (1996) notes that subjective ratings of action/effort-performance probabilities as well as perceived relations (e.g., frequency of cooccurrence) or correlations between actions/efforts and work-relevant performance outcomes (e.g., job satisfaction, self- and objective job performance ratings) have been considered in the literature (e.g., Kopelman, 1979; Lawler \& Suttle, 1973; see also Ilgen et al., 1981 for a review). Their meta-analytic findings suggest, however, that the magnitude of expectancy's relationship with work-related criteria (i.e., performance; effort expenditure; job application and turnover intentions; job, occupational, and organizational preference; and actual turnover and job/organizational choice) varied widely depending on whether studies considered the relationships within- or between-subjects, with within-subjects designs evidencing higher correlations (see also Kennedy et al., 1983). The potential for distinctive developmental or cross-domain patterning in expectancy judgments and relationships with outcomes has yet to be explored but provides a clear area of fruitful overlap with the study of aging workers' motivation. 
This echoes some authors who have critiqued Vroom and called for multiple effortperformance manipulations or "levels" in expectancy research (e.g., Ilgen et al., 1981), as effort expenditure and expectancy are necessarily interrelated: that is, individuals' "actual" and perceived control over performance depends on how much they devote themselves and their resources to performing well (see also Pinder, 2008). Little has been done to see how different person and context attributes relate to expectancy across the lifespan, although calls have been made to further study the relationships between expectancy and age: for example, Kooij and colleagues (2008) discuss the possible age-related influences of physical health, self-beliefs, and time on motivation and successful development via expectancy.

Some work- and age-relevant expectancy research has been dedicated to the components of Vroom's model including Erez \& Isen's (2002) job-relevant research on positive affect and its impact on expectancy motivation, or Tomasik and colleagues' (2017) more developmentally geared work on expectancy and goal systems (Tomasik et al., 2017). Expectancy has been applied within studies of skill updating as well, which is of particular relevance to aging populations and skill obsolescence (e.g., Sterns \& Dorsett, 1994; see also Sterns et al., 1994).

Self-Efficacy: Conceptual and Practical Definitions. Perceived self-efficacy is defined herein as "beliefs in one's capabilities to organize and execute the courses of action required to produce given levels of attainments" (Bandura, 1998, p. 624; see Table 1 and Figure 1, “1.2.2"). Although some authors, including Bandura himself, refer to self-efficacy as more of an agentsoutcomes construct (e.g., control over functioning as well as ultimate outcomes/life events; see also Skinner, 1996's discussion of this point), the classical treatment of self-efficacy is as an agents-means construct, concerned with confidence in behavioral (or behavioral sequence) performance rather than outcome relationships (e.g., Ajzen, 2002; Gist, 1987; Vancouver et al., 
2008). Furthermore, although most authors refer to "self-efficacy" to evoke its perceptual definition, we include "perceived" in this review to make clear the boundary between internal and external components of self-efficacy (see Bandura, 1986; Bandura, 1997).

Bandura (1977a, 1986) suggests that perceived self-efficacy varies along three dimensions: level or magnitude (i.e., difficulty of the task at hand), strength (i.e., confidence in performing the behavior), and generality (i.e., how generalizable versus local the expectations are). Self-efficacy is often practically defined in strength terms alone (Gist \& Mitchell, 1992), which parallels probability or confidence judgments of expectancy: even Bandura's (2006) own guide for developing self-efficacy scales focuses on level and strength, asking people to rate confidence at a number of different levels of challenge/performance (much like is recommended for expectancy measurement), rather than discussing generality. Smith (1989) and later work by Judge and colleagues (e.g., Judge, Erez, et al., 1998) proffered the concept of "generalized selfefficacy" to fill this gap, which entails “one's estimate of one's fundamental ability to cope, perform, and be successful” (Judge \& Bono, 2001, p. 80; see also Holladay \& Quiñones', 2003 conceptualization).

The concept of generality as it relates to self-efficacy points toward a fundamental difference between expectancy and self-efficacy: that is, there is a dispositional, domain-general component and/or "version" of perceived self-efficacy for which expectancy, which is predominantly considered in task/situation-specific contexts, does not have an analogue. Additionally, Pinder (2008) contends that perceived "self-efficacy is... somewhat a broader construct" than perceived expectancy, with the former entailing whether an individual believes they can do something and the latter entailing whether they believe they will do something (p. 367). Additionally, whereas perceived expectancy is focused on the link between effort and 
performance, perceived self-efficacy theory and research also considers other factors (e.g., affect) and the dynamic, generative capabilities of self-efficacy with respect to behavior, cognition, and emotional reactions (Gist \& Mitchell, 1992). Finally, self-efficacy does not take on an "actual" control form as does expectancy. Bandura's (1986) work posits that personal and situational resources and constraints do play a role in the formation of perceived self-efficacy, and there are so-called "environmental exigencies" (Vancouver et al., 2008, p. 36) that impact behavioral engagement and/or performance. These two components do not constitute a separate form of self-efficacy, however; instead, they are substantive influences on perceptual and behavioral processes that likely have bearing on functioning over the lifespan, in and outside of work.

Self-Efficacy: Theories and Models. The basis for most of the core attributes of perceived self-efficacy come from Bandura's (e.g., 1986) social cognitive theory. Social cognitive theory, an extension of social learning theory (e.g., Bandura, 1977b), focuses on the context in which human learning takes place, positing that personal factors (e.g., affect, biology, cognition), behavior, and environment dynamically and reciprocally influence behavioral learning across the lifespan. Perceived self-efficacy is central to this process, serving as a personal factor that can facilitate learning from others in the social environment. In Bandura's (1982) own terms, self-efficacy is a "mechanism" for human agency, through which sociostructural factors (e.g., economic conditions, family structures, culture) operate and produce behaviors (Bandura, 2001) and through which behaviors are used to shape sociostructural factors. Thus, functioning is a product of a multitude of causes, not the result of a unidirectional causal relationship across distal to proximal levels (or vice versa), which parallels how development and well-being are positioned in the lifespan literature (Baltes, 1987). 
With respect to the development and/or "cuing" of self-efficacy, many factors included in social cognitive theory are worth mentioning. Enactive mastery (i.e., past experience succeeding at a task), vicarious learning (i.e., observing important and competent others successfully performing a task and receiving reinforcement), verbal persuasion (i.e., encouragement from a trustworthy and competent individual), and psychological arousal (i.e., feelings of stress and/or energy) all serve as contributing factors to self-efficacy. These, in concert with personal, task, and situational appraisals, as well as "attributional analysis of experience" (Gist \& Mitchell, 1992, p. 189), contribute to self-efficacy perceptions (see Stajkovic \& Luthans, 1998b for a more detailed review). As noted by Gist and Mitchell (1992) information processing depth and accuracy also play a role in determining how self-efficacy perceptions form as well as how they translate into goal-directed behaviors and, ultimately, performance. Attribution theory (Weiner, 1985 ) intersects with self-efficacy in such models, as most appraisal processes require causal consideration of past and current events as well as evaluation of "where" factors relevant to the current task are located (i.e., externally, internally; under one's control, controllable; etc.).

Social cognitive theory has been heavily adopted by I/O psychology researchers and has been extended to models of career development across the lifespan (e.g., Lent et al., 1994; Lent \& Brown, 2006; Lent \& Brown, 2013). With respect to generalized self-efficacy, Judge and colleagues' work on core self-evaluations makes up the majority of recent theoretical space. Unlike some of the previously mentioned theories, this theoretical work "began" in the work context instead of migrating there, although original use of the term "core evaluations" and origins of the concept comes from Packer (1985) and takes a clinical perspective. Judge and colleagues (2005) contend that a broad personality trait referred to as "core self-evaluations," composed of self-esteem, generalized self-efficacy, neuroticism, and locus of control, represents 
the "fundamental assessments that people make about their worthiness, competence and capabilities" (Judge et al., 2005, p. 257; see also Judge et al., 2002). These dispositional selfassessments range from positive to negative, and they have been most often theoretically (and empirically) linked to subjective well-being at work (e.g., job satisfaction) and life more broadly (e.g., Judge et al., 2005). Various psychological mechanisms have been proposed to link core self-evaluations to well-being outcomes relevant to workers of all ages, including goal selfconcordance (e.g., Judge et al., 2005; see also Sheldon \& Elliot, 1999) and occupational selfconsistency (e.g., Korman, 1970), practical work success (e.g., Judge et al., 1997), and (mal)adaptive job behaviors (e.g., leaving vs. remaining in unsatisfying jobs; Spector, 1982).

Self-Efficacy: Age- and Work-Relevant Empirical Evidence. Both domain-general (e.g., generalized self-efficacy) and -specific forms of perceived self-efficacy have been studied in abundance in the work and lifespan literatures. Although the range of antecedents, outcomes, and mediators or moderators considered is outside of the scope of this review, there is a clear focus in the self-efficacy literature on how it promotes functioning (i.e., well-being, performance) across the lifespan, both in and outside of work. Broadly, self-efficacy applies to aging workers' general and context-specific competence beliefs: specifically, self-efficacy pertains to perceived capacities or limitations (e.g., for acquiring new skills, performance at work, managing agerelated limitations or challenges) and their implications for learning and development among aging workers (e.g., training, career investment and change, performance improvements or decrements; van Rooij, 2012).

In perhaps the best-known and well-cited perceived self-efficacy meta-analysis, Stajkovic and Luthans (1998a) considered the relationship between perceived self-efficacy (operationalized in specific forms) and work-related performance. They found a significant, 
positive weighted average correlation between perceived self-efficacy and performance, although the strength of this relationship varied depending on the type of study setting (i.e., lower correlations in natural settings as opposed to labs) and task complexity (i.e., lower correlations with more complex tasks; see also Sadri \& Robertson, 1993). Additional meta-analyses have found significant, positive relationships between perceived self-efficacy and vocational commitment (Chesnut \& Burley, 2015) and perceived vocational self-efficacy and career interests (e.g., mathematics self-efficacy and math interests; Rottinghaus et al., 2003), as well as a significant, negative relationship between self-efficacy (operationalized to include specific and general forms) and job burnout (Shoji et al., 2016).

Self-efficacy is included in a multitude of aging and workplace studies involving perceived capacities, potential, and limitations, including research pertaining to career development (e.g., Maurer, 2001), adaptation to change (e.g., Niessen et al., 2010), chronic illness and stigma (e.g., McGonagle \& Barnes-Farrell, 2014), effort expenditure in team contexts (Gärtner \& Hertel, 2020), and age-related stereotyping (e.g., Chiesa et al., 2016). Empirical research on generalized self-efficacy considers many similar work and lifespan functioning indicators as well. Meta-analytic evidence (e.g., Judge \& Bono, 2001) supports significant, positive mean correlations between generalized self-efficacy and job performance as well as job satisfaction. The broader core self-evaluation construct has been positively linked to performance (e.g., Erez \& Judge, 2001; Judge \& Bono, 2001) and negatively linked to work-family conflict (Boyar \& Mosley, 2007; see also Judge et al., 2004's review of empirical findings). Much attention has been devoted to situational factors in empirical studies of core self-evaluations (e.g., Best et al., 2005; Judge \& Hurst, 2007; Kacmar et al., 2009), generating evidence for the impact of personal (e.g., dispositional) and contextual influences on functioning outcomes (e.g., 
burnout, strain, career success) across the lifespan. These explorations are a prime example of "environmental exigencies" that act upon and interact with efficacy-oriented competence perceptions with age, shaping perceived capacities and outcomes.

Autonomy/Control: Conceptual and Practical Definitions. The final agentsmeans/competence constructs considered in this review are types of perceived autonomy and control. With the present focus on age and work, the primary form of perceived autonomy and control considered herein is job autonomy. Job autonomy (or job control) entails "the extent to which individual employees can structure and control how and when they do their particular job tasks" (Spector, 1986, p. 1006). The terms job control and job autonomy are often used interchangeably. Some authors distinguish between the two, with autonomy serving as a specific form of workplace control (i.e., over one's means; Ganster, 2011). This review treats them synonymously, however, given their general use in the theories and research discussed later.

Job autonomy has both "actual" and perceived forms represented in the literature (see Table 1 and Figure 1, “1.1.2” and "1.2.3”). These signify the objective existence (e.g., as a function of job characteristics, environmental attributes) and subjective experience of control at work. Job autonomy is frequently considered in distinct facets, such as those identified by Breaugh (1985), including work method autonomy (i.e., discretion/choice around methods used to complete work), work scheduling autonomy (i.e., discretion/choice around timing, scheduling, and sequencing of work), and work criterion autonomy (i.e., discretion/choice around selecting or modifying performance evaluation criteria). This three-facet approach to job autonomy has been supported in multiple studies (e.g., Breaugh, 1999; Sadler-Smith et al., 2003) and has been widely adopted through recent years (e.g., Daniels et al., 2018; Theurer et al., 2018). 
Karasek’s (1985) Job Content Questionnaire also takes a multidimensional approach, measuring job control as a function of decision authority (i.e., workers' latitude to make decisions on the job) and skill discretion (i.e., breadth of skills used by workers in their job). This approach has been criticized for confounding control with job complexity and other constructs (e.g., Ganster \& Schaubroeck, 1991). In response, some global or unitary scales have been created, including Ganster's (1989) measure, which comprises a variety of job control-relevant topics such as task variety, task order, pacing, break scheduling, and physical environment arrangement (see Smith et al., 1997; see also Breaugh, 1998; Hackman \& Oldham, 1974, 1975). Despite this variability, consensus seems to be that multiple types of autonomy are important to consider conceptually and operationally, and that this must be done while differentiating control from other constructs like interdependence or complexity.

Most of the preceding discussion comes from studies and measures of perceived job autonomy, but "actual" job autonomy is similarly variable. Some studies consider job characteristics from supervisor evaluations (e.g., Elsass \& Veiga, 1997), aggregated unit evaluations (e.g., de Jonge et al., 1999) or judge ratings (e.g., Glass et al., 1993; McKnight \& Glass, 1995), an individual's job level (e.g., Kröger, 2017), self-evaluated opportunities for control (e.g., the Maastricht Autonomy Questionnaire, de Jonge, 1995; see also Karasek, 1979), or a combination of multiple sources (e.g., job descriptions and occupational indices, Spector \& Jex, 1991). Additional work considering occupation-level characteristics related to control has been conducted (e.g., Alfredsson et al., 1982; Ford \& Wooldridge, 2012; LaCroix \& Haynes, 1986; Taris et al., 2005), but these risk disregarding job variability within occupations, or not accounting for individual-level factors such as socioeconomic status that covary with occupation (Ganster \& Fusilier, 1989; Fox et al., 1993). Both "actual" and perceived job autonomy relate to 
how individuals are supported or constrained by their job in performing their work how and at the level they desire.

Autonomy/Control: Theories and Models. The theoretical elaboration of job autonomy and control, whether perceived or "actual," has primarily taken place in the occupational health literature and is based in the construal of job autonomy as a "resource" to offset job demands.

Hackman and Oldham's work is based in broad theories of motivation and individual differences, including motivation-hygiene theory (Herzberg et al., 1959), activation theory (Scott, 1966), and work on interactions between objective task attributes and individuals (Turner \& Lawrence, 1965). Overall, the job characteristics model describes interactive effects of individual needs and job characteristics in prompting psychological states and outcomes of relevance to personal and professional functioning (e.g., well-being, performance). The job characteristic of autonomy is predicted to contribute to experienced responsibility for work (i.e., a means-ends control belief), as individuals are provided with the discretion to expend effort and make decisions that dictate their success or failure. Revisions to the job characteristics model have expanded the theory to include contextual variables (e.g., national culture, Hauff et al., 2015), individual differences such as trait positive affect (e.g., Oerlemans \& Bakker, 2018), negative affect (e.g., Houkes et al., 2003), and Big 5 personality traits (e.g., van den Berg \& Feij, 2003). Moreover, Humphrey and colleagues' (2007) expansion of the job characteristics model added more motivational work characteristics, including an expansion of autonomy to include three sub-types (i.e., decision-making, scheduling, and methods), as well as more social characteristics (e.g., support, interdependence) and context characteristics (e.g., physical demands, ergonomics). Barrick et al. (2013) similarly expanded the job characteristics model to 
focus on broader, implicit motivational strivings and goals, personality, and both task and context characteristics that contribute to work outcomes.

Karasek's (1979) job demands-control model contends that interactions - that is, convergence or divergence-between an individual's job stressors and decision latitude produce well-being outcomes. Jobs are defined as belonging to one of four "types" based on possible demand and control interactions: passive (i.e., low demands $\times$ low control), low strain (i.e., low demands $\times$ high control), active (i.e., high demands $\times$ high control), and high strain (i.e., high demands $\times$ low control). This model, although pervasive in the literature, has garnered very little support for its interactive hypotheses (e.g., see reviews from Fila, 2016; Kain \& Jex, 2010; Taris, 2006; empirical work by Keller et al., 2016), although its direct or additive effects are often supported when tested with sufficiently large samples (e.g., Fila et al., 2017; Häusser et al., 2010). Expansions of the model to include other variables such as resources and social support (e.g., Johnson \& Hall, 1988; Karasek \& Theorell, 1990) have been attempted to address some of these shortcomings with similarly limited support (e.g., de Lange et al., 2003; Landsbergis et al., 1992).

Demerouti and colleagues' (2001) job demands-resources model has garnered much greater acceptance and support in recent decades (Bakker \& Demerouti, 2017). Similar to the job characteristics and job demands-control models, the job demands-resources model originated to explain well-being outcomes that result from working conditions, and it is based in stress and well-being literatures (e.g., Hockey’s, 1993, control model of demand management; Antonovski's, 1987, work on health promotion and maintenance). In Demerouti and colleagues' (2001) model, demands are defined as physical, social, or organizational components of an individual's job that "require sustained physical or mental effort and are therefore associated 
with certain physiological and psychological costs" (p. 501). Resources, on the other hand, are "physical, psychological, social, or organizational aspects of the job that may...(a) be functional in achieving work goals; (b) reduce job demands at [sic] the associated physiological and psychological costs; (c) stimulate personal growth and development” (p. 501). Importantly, these resources are external to the individual and thus do not include cognitive or behavioral patterns internal to individuals. Job control serves as an organizational resource within this framework, helping protect individuals' well-being in the face of job demands. Unlike Karasek's (1979) approach, Demerouti and colleagues (2001) focus on the independent contribution of demands and control on burnout; since its initial publication, the job demands-resources model has been extended to a wealth of other functioning outcomes (Bakker \& Demerouti, 2017). Additional work has been conducted considering the role an individual's resources, including other control beliefs such as generalized self-efficacy, may play in the outcomes of experienced job demands and resources (e.g., Xanthopoulou et al., 2007; Xanthopoulou et al., 2008).

The final theoretical perspective of note for the discussion of autonomy is Hobfoll's (1989) conservation of resources theory. Perhaps even more broadly than the three previous occupational health theories, conservation of resources theory attempts to account for the processes that lead to burnout (and other well-being outcomes). Taking a resource perspective, this theory suggests that stress at work or in other contexts is a result of resource threat, loss, or inadequate gain following resource investment. Resources are defined broadly as "objects, personal characteristics, conditions or energies that are valued in their own right or that are valued because they act as conduits to the achievement or protection of valued resources" (Hobfoll, 2001, p. 339). Perceived (and "actual") control fall within the purview of a resource (e.g., Chen et al., 2009). Unlike the other theories, it directly relates to lifespan-informed theories 
of goal selection and striving, functioning, and cycles of gains and losses with age (e.g., Hobfoll \& Wells, 1998; Huffman et al., 2013; Kooij \& Van de Voorde, 2011).

Autonomy/Control: Age- and Work-Relevant Empirical Evidence. As with selfefficacy, job autonomy and control — in both objective and subjective senses — have been studied abundantly in the work and lifespan literatures. With respect to their applications to age- and aging-relevant issues at work, then, job autonomy and control have much to contribute, particularly pertaining to job design and functioning outcomes. Specifically, there is clear overlap between the study of perceived job autonomy and control and optimal job design (while considering individual differences, contextual factors, and other forms of control) for aging workers, identifying the aspects of jobs (i.e., demands, resources) that are congruent with and supportive of older workers' needs, well-being, and performance (Truxillo et al., 2012).

Job autonomy and control have been consistently linked to positive functioning outcomes in and outside of work across the lifespan. In Spector's (1986) meta-analysis of autonomy and participative decision-making, autonomy was positively related to various beneficial outcomes (work satisfaction, motivation, commitment, performance) and negatively related to adverse outcomes (physical symptoms, emotional distress). Unfortunately, given the broad scope of the job autonomy and control literature, other quantitative reviews are few and far between outside of model-specific investigations (e.g., the Fried \& Ferris, 1987, job characteristics model metaanalysis noted earlier; Halbesleben's, 2006, conservation of resources and burnout metaanalysis). However, there is a wealth of individual empirical studies that consider job control and autonomy with similar results regarding the positive impact of control on work and lifespan functioning. 
A lingering question is "where" autonomy resides within the organization (e.g., in the person, the work group, the task), and, consequently, where it can and should be measured and intervened upon. Additionally, the contention that more control is necessarily better is not entirely true, and it depends on other factors such as individual coping strategies and an individual's "need" for control (i.e., desire or propensity to enact control; de Rijk et al., 1998). Other control constructs, including perceived or general self-efficacy (e.g., Grau et al., 2001; Salanova et al., 2002) and locus of control (e.g., Daniels \& Guppy, 1994; Meier et al., 2008), may play a role as well. They are often considered in empirical studies with job autonomy, serving as antecedents, moderators, mediators, and/or outcomes.

Job autonomy and control are extensively discussed and studied from a work and lifespan perspective, and often more directly than are expectancy or self-efficacy. For example, crosssectional and longitudinal research has explored whether or not autonomy-work outcome relationships (e.g., performance, satisfaction) vary based on individuals' age, finding that some relationships are stronger (e.g., job self-efficacy, job performance) for relatively older adults while others are weaker (e.g., job satisfaction, affective commitment; Ng \& Feldman, 2015). Certain tenets of Karasek's (1979) job demands-control model have even been upheld when considering age differences: Shultz and colleagues (2010) found evidence to suggest that different forms of control buffer against different demands depending on age (e.g., time deadline demands and autonomy buffered against reported stress among older and not younger workers; Shultz et al., 2010; see also Perrewé \& Anthony, 1990). Additionally, job control has been found to moderate the relationship between age-contingent coping strategy use and work strain (Hertel et al., 2015), such that older adults engage in more active problem-focused coping. Age also moderates the relationship between needs-supplies fit for job control (construed as an "intrinsic 
growth value") and job satisfaction such that (mis)fit has a more substantial impact on the subjective well-being of relatively older workers (Krumm et al., 2013; see also Zacher et al., 2014). The practice of considering job control and autonomy as they relate to "needs," "work values," or "fit" is prevalent in this area of the literature, and both primary and meta-analytic evidence indeed suggests that autonomy is of greater "importance" for relatively older workers vis-à-vis certain functioning outcomes (Besen et al., 2015; Hertel et al., 2013; Kooij et al., 2008; see also Zacher \& Schmitt, 2016, for a review of age, work characteristics, and occupational well-being).

Job autonomy and control are also considered with respect to successful aging-promoting behaviors, and resource- and control-promoting behaviors. These empirical studies include such phenomena as job crafting (Petrou et al., 2012; Tims et al., 2013; see also Kooij et al., 2015) and self-regulatory enacted control, studied alone and in relation to functioning outcomes (e.g., performance, Bajor \& Baltes, 2003; work ability, Müller et al., 2017; depressive symptoms, Weigl et al., 2013). Thus, having "actual" and/or perceived control over job-relevant means translates into a number of important outcomes for individuals aging in the work context, and it is linked to lifespan theories of aging, control, and self-regulated development to explain agebased differences in functioning outcomes (e.g., Besen et al., 2015).

Means-Ends/Contingency Constructs. Now that agents-means control constructs have been reviewed, we will review means-ends or contingency control constructs. The control constructs that fall within this category include instrumentality and locus of control.

Instrumentality: Conceptual and Practical Definitions. Whereas expectancy answers the question "will I perform at this level?," self-efficacy answers "can I perform at this level?," and autonomy/control answers "do I have the discretion and choice required to perform at this 
level?," instrumentality answers "will I receive desired outcomes as a result of my performance?" Thus, similar to expectancy, perceived instrumentality refers to a probabilistic judgment about control, although this judgment centers on performance-outcome contingencies rather than effort-performance competence assessments. Instrumentality hails from the same motivational tradition as does expectancy but is more closely linked to the desirability and importance, or valence, of second-level outcomes (e.g., rewards and compensation, praise) that follow from performance. Thus, performance is seen as instrumental to the extent that it does or is believed to propagate desirable, positively valenced outcomes for individuals, as well as help them avoid undesirable, negatively valenced outcomes. As with expectancy, instrumentality can take on "actual" and perceived forms (see Table 1 and Figure 1, "1.1.3" and "1.2.4"). However, the measurement of "actual" instrumentality is not well represented in the literature. The closest form of "actual" instrumentality considered in the literature are rewards, compensation, and promotion policies and practices; however, these objective policies and practices filter through individuals' perceptions (e.g., of organizational justice) to impact instrumental beliefs (Parker et al., 2011).

Instrumentality: Theories and Models. Given the detailed coverage of expectancy theories earlier in the review, overlap between previously mentioned theories and instrumentality will not be reiterated. However, there are additional theoretical perspectives linked chiefly to instrumentality of relevance to lifespan functioning and work (see Mitchell \& Biglan, 1971).

Graen's (1969) modified instrumentality theory is a variation on Vroom's (1964) original expectancy theory. This theory inserts particular reward boundary conditions, such as a clear contingency between performance and reward (as opposed to a reward that was not contingent on effective performance), and a new motivational force and effort formula alongside 
expectancy, instrumentality, and valence. This formula notably includes both external role considerations, including experienced pressure to comply and what others expect of a particular role, and internal pressures, such as the desirability of intrinsic consequences from performance. These forces are used to describe job satisfaction and performance outcomes, with both outcomes resulting from relevant and appropriate actions and the ultimate "resolution of [internal and external] pressures" (Graen, 1969, p. 23). This version of instrumentality theory takes a more explicit account of both internal and external "ends," as well as environmental pressures to perform, that impact motivation and functioning with age.

This conceptualization of instrumentality is linked to House and Mitchell's (1975) pathgoal theory of leadership as well. Path-goal leadership theory aligns with one of the origins of Vroom's (1964) work, Georgopoulos and colleagues' (1957) path-goal approach to productivity (Georgopoulos et al., 1957), and itself serves as a progenitor for additional theories of leadership (e.g., charismatic leadership, House, 1977). Path-goal leadership theory suggests that leader behaviors serve to guide their followers in attaining goals through specific means (see also House, 1996). Leaders are core to subordinate satisfaction and performance, influencing their motivation and empowerment by complementing subordinate abilities and attributes_-including other forms of control such as perceived locus of control and self-efficacy-as well as work environments. By doing so, leaders support followers' success in reaching desirable outcomes. This theory is quite broad and relevant to expectancy as well, but it takes a more explicit account of instrumentality relationships (e.g., performance-reward contingencies) than do other approaches. It also presents leadership behaviors and approaches that can foster perceived instrumentality and ultimate success for individuals and work units, which have been supported to some extent in research (e.g., Dixon \& Hart, 2010; Schriesheim et al., 2006). 
Theories of equity and justice (e.g., Adams, 1965; Greenberg, 1987) are similarly relevant to understanding the role of perceived instrumentality in the work context. The range of theories and constructs used to study equity and justice in organizations are outside the scope of the present review, but they possess common attributes that are relevant to instrumentality, and to work and aging. Colquitt and colleagues (2001) present two of relevance: allocation or distribution consistency (i.e., distributive justice, Adams, 1965; Leventhal, 1976), and procedure or process control (i.e., procedural justice, Thibaut \& Walker, 1975; Colquitt et al., 2001). While procedural justice refers to fairness perceptions of decision-making processes and procedures (e.g., performance appraisal), distributive justice refers to fairness perceptions of subsequent outcomes in organizations (e.g., rewards and recognition for performance). Procedural justice can be judged according to a number of criteria of which three are particularly relevant to perceived instrumentality: consistency, which entails the stable application of procedures across people and time; accuracy, which is the degree to which procedures are based on informed opinions and complete data; and correctability, or the ability to modify or reverse decisions during procedure development and implementation (Leventhal, 1980). Distributive justice is judged more generally upon the perceived appropriateness or proportionality of outcomes (i.e., ends), given an individual's contributions (i.e., means; Deutsch, 1975; Leventhal, 1976). As such, equity and justice theories are quite relevant to understanding the underpinnings and influences of an individual's instrumentality perceptions, as well as the "actual" instrumentality (i.e., as a function of procedural and distributive practices in an organization) that affects justice.

Finally, it is worth noting that instrumentality has been used as a theoretical mechanism by which norms emerge in social groups. Opp (2001) outlines a theory of norm emergence, which is centered on the "instrumentality proposition": that "norms emerge if they are 
instrumental for attaining the goals of a group of actors" (p. 101). More specifically, norms pertain to behaviors and performance (i.e., means) that are proposed to satisfy the needs and goals (i.e., ends) of a group of individuals. Once the perceived instrumentality of a behavioral performance is established, sharedness and acceptance of norms, sanctioning mechanisms (i.e., reinforcement of norm compliance), and behavioral regularity emerges in social units. These can emerge from top-down (e.g., leaders who identify instrumentalities between means and ends and share subsequent expectations with followers) or bottom-up processes (e.g., individuals in a collective who identify instrumentalities and create a norm through aggregation, social interaction, and reciprocal negotiation over time).

Although this approach to norm emergence has not been explicitly adopted in the aging and work literature, it is implied insomuch as a) individual behaviors are engaged in due to their instrumentality and b) patterns of behavior can emerge through compilation across a focal unit's members (e.g., see Raver et al., 2012). It also presents clear parallels and intersections with developmental perspectives on work phenomena, as well as issues of employee socialization and culture - both of which are relevant to work across the lifespan (Ellis et al., 2015).

Instrumentality: Age- and Work-Relevant Empirical Evidence. A small selection of lifespan- and well-being-relevant studies have been conducted with instrumentality: for example, McCarthy and colleagues (2010) conducted a study of manager instrumentality beliefs regarding work-life balance policies and practices, and the impact of these beliefs on employee policy awareness, use, and satisfaction (McCarthy et al., 2010). Perceived instrumentality has been empirically considered in motivational studies of potential relevance to lifespan development and work, such as studies on self-regulation and goal orientation among adults and students as a function of perceived instrumentality and future time perspective (Lens et al., 2001; Simons et 
al., 2000), and on occupational decision-making (Brooks \& Betz, 1990). With respect to "actual" instrumentality, some authors have discussed the concept in the context of regulatory fit and goal pursuit (i.e., with respect to chosen goal strategies and actual/perceived instrumentality; Spiegel et al., 2004). Despite this relative paucity of literature, instrumentality has clear applications to age- and aging-relevant issues at work that are worth exploring, particularly with respect to aging workers' contingency judgments and motivated decision-making in context. Specifically, instrumentality pertains to objective and subjective performance-outcome probabilities within and across complex social systems - chiefly, organizations with a variety of influential actors (e.g., leaders), units (e.g., teams), and temporal forces in which employees evaluate expectations, interdependence, rewards, and fairness and engage in motivational pursuits accordingly (e.g., referencing retirement norms, revising performance goals, monitoring attainment relative to peers, social standards, and observed outcomes; see discussion in Gärtner et al., 2019).

Locus of Control: Conceptual and Practical Definitions. Perceived locus of control can be defined as "the extent to which people believe that they have control over their own fate" $(\mathrm{Ng}$ et al., 2006, p. 1057), or, more concretely, "a belief that a response will, or will not, influence the attainment of reinforcement" (Furnham \& Steele, 1993, p. 444; see Table 1 and Figure 1, “1.2.5”). When considered dispositionally (i.e., as a personality trait), perceived locus of control can be differentiated into "internal" and "external" forms. Individuals with an internal locus of control perceive themselves as in control of their "fate," or life events and outcomes (i.e., means), while individuals with an external locus of control do not perceive themselves to be in control of events, and instead attribute outcomes to aspects of the environment or luck (Rotter, 1966). Perceived locus of control purportedly differs from self-determination and causality orientation, in that it concerns control over the outcomes of events rather than the perceived 
source of behavioral initiation and regulation in specific contexts (Deci \& Ryan, 1985b; see Table 1, “1.4.1”).

Unlike perceived self-efficacy, which is a competency belief, perceived locus of control is a contingency belief, as it entails the attribution of control for ultimate event outcomes (Strauser et al., 2002). Indeed, it is apparent that this construct applies to a separate part of the “control equation" from perceived self-efficacy (Bandura, 1977a; Peterson \& Stunkard, 1992; Rotter, 1966). This is especially true when considering more specific forms of perceived selfefficacy and locus of control (e.g., in a particular domain or situation; Strecher et al., 1986; see also Bandura, 1997; Judge, Locke, et al., 1998). Johnson and colleagues (2015) contend that perceived locus of control is largely a function of environmental responsivity, predictability, and controllability (i.e., contingency) rather than a function of self-appraisals of ability (i.e., competency).

Given this clear link to the environment, two questions arise: first, how does this translate into "actual" locus of control, and second, how does perceived locus of control differ from perceived instrumentality? Answers to both questions largely parallel the distinctions between perceived self-efficacy, "actual" self-efficacy, and expectancy. First, as with perceived selfefficacy, "actual" locus of control does not exist. Instead, personal and environmental resources and constraints impact performance-outcome contingencies, such as by providing just or unjust outcomes or "reinforcers," but do not form or constitute an objective control locus. In answer to the second question, whereas perceived instrumentality pertains to whether an individual believes they will receive desired outcomes as a result of performance, perceived locus of control pertains to whether the outcomes they receive are a result of their performance. This belief, both 
in and across domains, has important theoretical and empirical implications for patterns of behavior and functioning across the lifespan in and outside of the workplace.

Locus of Control: Theories and Models. Aside from theoretical developments regarding core self-evaluations, Rotter's (1966) theoretical work on (general) locus of control is the formative basis for this literature as well as its numerous domain-specific outcroppings (Furnham $\&$ Steele, 1993). Centered on social learning theory (e.g., Rotter, 1955), locus of control results from reinforcement over time. Specifically, as individuals gain experience with particular behaviors being followed by particular outcomes, they come to expect certain outcomes to follow specific behaviors (i.e., an instrumentality belief, termed "expectancy" by Rotter). As individuals age, they learn about events and outcomes that are causally related and which are not - that is, which outcomes are contingent upon events and which happen independently. They then make instrumental and non-instrumental generalizations to similar situations based on this learning.

A number of distinct "types" of locus of control have emerged in the literature (e.g., health, marriage, academics, sports achievements, parenting, work), following from the same situation-based tradition of Rotter's social learning theory. Furnham and Steele (1993) describe three domain-specificity approaches: a) behavioral spheres of locus of control (i.e., personal, interpersonal, sociopolitical; Paulhus, 1983; Paulhus \& Christie, 1981); b) control at different levels and times (i.e., predictive, illusory, vicarious, interpretive; Rothbaum et al., 1982) and in relation to enacted control processes (i.e., primary and secondary control, discussed later; Rothbaum et al., 1982; Weisz et al., 1984); or c) direct domain specification (e.g., the creation of a work locus of control scale; Spector, 1988). It is important to note as well that Spector's (1988) work domain locus of control scale, as with some others, is more generally referenced rather than 
self-referent (i.e., the items refer to "work" and "people" in general) and thus represent control beliefs about work as it applies to oneself as well as to others. The concept of possessing multiple locus of control beliefs that differ based on situation and source is explored further (at least with respect to individual differences) in implicit theories of personality (e.g., Chiu et al., 1997; Dweck et al., 1995). Fittingly, locus of control and implicit personality theory have been discussed together with respect to organizational "internality norms" (Pansu, 1997) and causal location and stability attributions in achievement contexts (e.g., Weiner et al., 1972). Implicit theories generally focus on both performance and outcomes rather than outcomes alone, however (e.g., including efficacy- and locus of control-type beliefs predicting goal selection and striving; Dweck \& Leggett, 1988).

Locus of Control: Age- and Work-Relevant Empirical Evidence. Of the many forms of perceived locus of control in the literature, general locus of control and work locus of control are of most relevance and will be focused on herein. In parallel with self-efficacy, both general and work-specific locus of control apply to aging workers' general and context-specific contingency beliefs: specifically, locus of control pertains to the perceived source of experienced results and rewards (e.g., promotion or job loss, age-related gains and losses) and the implications of these beliefs on various levels of decision-making for aging workers (e.g., career transitions based on perceived controllability of aging or occupational outcomes; Van der Horst et al., 2017).

A wealth of meta-analytic evidence on general and work locus of control suggests support for positive functioning outcomes in and outside of work (e.g., performance, safety, physical and psychological well-being) for individuals with an internal locus of control (e.g., Alarcon et al., 2009; Ng et al., 2006; Wang et al., 2010). Primary studies pertaining to workplace and lifespan functioning abound as well, in addition to research integrating perceived locus of 
control with additional control constructs (e.g., Daniels \& Guppy, 1994; Fusilier et al., 1987;

Rodríguez et al., 2001; Wu et al., 2015). Within-person research has been done in the developmental literature that pertains to the aging and work context, much of which attempts to determine the trajectory of locus of control beliefs over time. These results have been mixed (e.g., Degelman et al., 1991; Hale \& Cochran, 1986), with some studies finding support for increasing internality over time and others for increasing externality (see Grob et al., 1999 for a discussion). Most authors attribute these discrepancies to domain generality or specificity and age range restriction (e.g., Grob et al., 1999; Lachman, 1986), while others contend that certain forms of control are more adaptive for certain situations across the lifespan (e.g., locus of control for events vs. event consequences; Gatz et al., 1986). At the intersection of development and work, locus of control has been considered in concert with career decision-making and retirement (e.g., see O'Brien's, 1984, review) as well as other constructs such as memory and information processing capacity (e.g., Lachman, 1991; Wolinsky et al., 2010), job satisfaction (e.g., Siu et al., 2001; White \& Spector, 1987), and self-regulatory and motivational behaviors (e.g., enacted control; Brandtstädter \& Rothermund, 1994).

\section{Enacted Control: Constructs, Theory, and Research}

To conclude the review portion of this paper, primary and secondary control are next discussed together with respect to conceptualization, theory, and research. At a general level, enacted control aligns with questions of how individuals "age successfully" (i.e., maximize sustainable employability, well-being, and functioning) in and outside of work, and where "actual" and perceived supports and constraints intersect with these behavioral efforts.

Control Striving \& (Developmental) Self-Regulation Constructs. Enacted control entails individual engagement in control strategies to self-regulate development and functioning 
across the lifespan. These strategies are chiefly related to primary and/or secondary control striving; they are employed in response to perceived control (or lack thereof), and in the service of well-being and control maximization across the lifespan. In other words, enacted control and its requisite strategies concern minimizing losses and maximizing gains (e.g., of resources, functioning) with age.

Primary and Secondary Control: Conceptual and Practical Definitions. In order to maximize control and functioning throughout one's development, individuals engage in primary control and secondary control-related strategies generally and in specific domains (e.g., work). Primary control (see Table 1 and Figure 1, “1.3.1”) broadly refers to individuals' attempts to change their environment to be in line with needs and goals, while secondary control ("1.3.2") refers to individuals' attempts to change themselves (e.g., goals, perceived needs) to be in line with their environment (e.g., with respect to constraints and limitations; Heckhausen et al., 2010; see also Folkman et al., 1986; Rothbaum et al., 1982). The concepts of primary and secondary control are widely represented in various domains of the lifespan development and selfregulation literatures, and their various strategies are postulated to vary in relevance and adaptivity depending on time and context. Both types of control are "enacted" insomuch as they are (pro)active attempts on the part of individuals to make self or environment adjustments, and they can entail a variety of affective, behavioral, and cognitive monitoring and striving strategies (Heckhausen \& Schulz, 1995; Heckhausen et al., 2010).

Primary control capacity is treated as the ultimate target of control striving, with secondary control strategies "maintain[ing], protect[ing], focus[ing], and enhanc[ing] motivational resources for primary control striving" (Heckhausen \& Schulz, 1999b, p. 606) in short- and longer-term primary control maintenance or expansion. Self-directed control strategies 
can support and augment environment-directed control strategies, through helping maintain resources and reaffirm motivational commitment and/or compensating for perceived loss or failure. A range of domain-general and -specific measurement approaches are used for assessing primary and secondary control, in line with the multitude of work and lifespan-relevant control striving and self-regulation theories discussed next.

Primary and Secondary Control: Theories and Models. Given the range of possible theoretical perspectives to discuss in this section, we focus on those of most relevance to aging and work, as well as to integration with "actual" and perceived control constructs. For lifespan development theories, "functioning" outcomes (or "successful aging" metrics) are context dependent. Thus, each of the theories discussed are meant to explain adaptive and maladaptive enacted control across the lifespan, although the exact nature of adaptivity and functioning are dependent upon a multitude of interacting factors - including but by no means limited to "actual" and perceived control.

Heckhausen and colleagues' theoretical work on primary and secondary control is fundamental to the conceptualization of control striving and developmental self-regulation in and outside of work, as well as to the recognition of "actual" and perceived control as formative influences in development across the lifespan. The motivational theory of lifespan development (and its predecessor, the motivational theory of control), presents selective and compensatory sub-types of primary and secondary control. These all serve as mechanisms for the exertion and maintenance of control throughout development. This approach is inherently temporal, involving sequential goal "action cycles" (i.e., goal selection, striving, disengagement) that occur in a generally predictable fashion over the lifespan (e.g., with respect to developmental goals and “deadlines" for normative events, life transitions). Certain mechanisms of control are more or 
less adaptive during these life phases, and their adaptivity is contingent upon available resources, opportunities, and constraints (Heckhausen et al., 2010). The motivational theory of lifespan development is a clear complement to the "actual" and perceived control literature discussed earlier: it includes objective and perceived opportunities and constraints, considers control perceptions as an internal motivational resource, and focuses on developmental deadlines and social reference points as guides for control enactment and controllability perceptions over time (Heckhausen et al., 2010; Schulz \& Heckhausen, 1999).

Brandtstädter and Renner's (1990) dual-process model of assimilative and accommodative coping conceptualizes "actual" and perceived control as central to enacted control mechanisms as well. Rather than referring to primary and secondary control types, this perspective adopts the terms "tenacious goal pursuit" and "flexible goal adjustment." More so than the motivational theory of lifespan development, these concepts are treated as regulatory coping responses (although the difference between "control," "regulation," and "coping" is muddy; Skinner, 1999). These coping responses are made in answer to perceived discrepancies between current or anticipated life situation(s) and desired life situation(s) and a number of cognitive, evaluative, behavioral, and affective cues and experiences. Thus, Brandtstädter and Renner's (1990) approach is more "fit-focused" than is Heckhausen and colleagues' work (Aldwin et al., 2011, p. 565).

Two additional lifespan development theories pertain to primary and secondary enacted control as well, although they do so less overtly. Baltes and Baltes' (1990) model of selective optimization with compensation (as well as Freund and Baltes', 2000, action-theory framework) constitutes a meta-theory of goal setting and attainment through goal-relevant means. Processes of selection, optimization, and compensation are forms of enacted control over goal planning and 
"preactional" action regulation and monitoring. Selected goals and striving mechanisms can differ in their target (e.g., environment vs. self) in addition to being influenced or determined by life circumstances (e.g., constraints and resources, social expectations). The second theory, Carstensen and colleagues' (1999) socioemotional selectivity theory, presents an account of why certain goals are prioritized across the lifespan. This theory is inherently social and temporal, framing the relative prioritization of goals as a function of individuals' future time perspective, or their temporally self-contextualized "place" in life. Specifically, relatively older individuals select situations that they know will afford them emotional meaning and satisfaction—such as those with known and meaningful others. Control and emotions (e.g., emotion regulation, wellbeing) have been fittingly integrated in offshoots of socioemotional selectivity theory (e.g., Charles', 2010, strength and vulnerability integration model) as well as other theories of lifespan development (e.g., Urry and Gross', 2010, selective optimization with compensation and emotion regulation framework; see also Scheibe \& Zacher, 2013). The concept of possessing "more time" (i.e., an expansive or open-ended future time perspective) can be construed as a form of perceived control as well, as it provides time to "work with" in choosing and striving toward goals.

A review of theory in this area of the literature would be remiss to omit Zacher and colleagues' (2016) integration of action regulation theory with lifespan development principles in the context of work and aging (Zacher et al., 2016). Action regulation theory, which overlaps heavily with previously discussed theory (e.g., expectancy theory, social cognitive theory) as well as self-regulation and control theory, focuses on the "mental regulation of work tasks and active, goal-directed behavior in the work context" (Zacher et al., 2016, p. 287; see Frese \& Sabini, 1985; Frese \& Zapf, 1994). The theory is based on assumptions of human agency and 
environmental influenceability, as well as on the idea that "purposeful" behaviors (e.g., enacted control) occur in sequence over time and across multiple levels of action regulation. Translated to a lifespan perspective, this meta-theory highlights the impact of age-related changes on stages of the action regulation cycle and enacted control strategies, as well as the impact of time (e.g., future time perspective, developmental deadlines) and context on regulated development, behavior, and opportunities at work. This meta-theoretical approach provides an integrative format in which to consider a multitude of age-related changes (i.e., cognitive, personality, motivation, socioemotional experience), and "actual" and perceived control contingencies, as they pertain to control enactment at work.

Finally, Sheldon and Elliot's (1999) goal self-concordance theory presents a lifespanrelevant account of the goal commitment and striving process. This theory contends that the degree to which goals are self-integrated impacts motivational and well-being outcomes as well as the control enactment used to self-regulate the control striving process. Moreover, goal "fit" or integration is dependent upon perceived control over goal commitment and pursuit. Control perceptions (and to some extent "actual control") are thus an integral part of goal-directed selfregulation and enacted control within the goal self-concordance framework, and their over-time well-being impacts are of fundamental importance in the literature (e.g., Gaudreau et al., 2012; Koestner et al., 2002).

Primary and Secondary Control: Age- and Work-Relevant Empirical Evidence. Even more so than the previously discussed control constructs, primary and secondary enacted control bear clear applications to issues of age and aging at work. Specifically, these concepts relate to understanding how workers act upon the work environment and themselves, respectively, to fit priorities and current opportunities and capacities. Central to this are also questions of how 
workplaces can prepare workers to engage in these behaviors adaptively and with diverse means to fulfill mutual employee and organizational needs (e.g., generativity needs met through mentoring experiences; Doerwald et al., 2021).

With respect to primary and secondary control's relationships with lifespan functioning in and outside of work, the literature is diffuse. When investigated in the motivational theory of lifespan development tradition, much literature is devoted to occupational transitions (e.g., school-to-work, unemployment or job loss) and goal engagement and disengagement (see Rudolph, 2016). Limited research has considered functioning outcomes (e.g., life satisfaction, physical and mental health, goal progress) in the context of work or employment. Mixed results have been observed, with certain control strategies serving as more adaptive with respect to wellbeing depending on other conditions (e.g., employment status; Körner et al., 2012; daily workload, Hoppmann \& Klumb, 2012; congruence between perceived and enacted control, Shane \& Heckhausen, 2012; occupational uncertainty, Körner et al., 2015; Pavlova \& Silbereisen, 2013). Indeed, growing consensus seems to be that well-being enhancement and strain buffering can occur from all forms of enacted control, but that these effects depend on a number of personal and contextual factors that shape an individual's perceived control (e.g., agerelated changes, Broadbent et al., 2014; de Quadros-Wander et al., 2014; family demands, social change, Grümer et al., 2013; functional (in)dependence, Hamm et al., 2017).

Mixed findings have emerged from the tenacious goal pursuit and flexible goal adjustment literature as well, with evidence of moderated relationships in some cases (e.g., gender, Abraham \& Hansson, 1996; age, Niessen et al., 2011). However, evidence points to the relevance of both enacted control tenacity and flexibility to well-being outcomes, directly and through buffering effects (e.g., positive and negative affectivity, Heyl et al., 2007; psychological 
functioning, Kubicek et al., 2011; work satisfaction, occupational well-being, Abraham \& Hansson, 1996; mental health, Niessen et al., 2011; life satisfaction, Bailly et al., 2014; depressive symptoms, Hajek \& König, 2017; Kubicek et al., 2011; negative emotions and chronic pain, Goossens et al., 2010). Notably, there is a good deal of meta-analytic support for multi-domain performance and well-being benefits of selective optimization with compensation (e.g., Moghimi et al., 2017) and future time perspective (e.g., Kooij et al., 2018; Rudolph et al., 2018), as well as primary study support for positive outcomes of goal self-concordance.

A good deal of research has also considered how enacted control engagement shifts with age. Some authors model multiple possible trajectories of control strategies over time (e.g., Martinent et al., 2017), while others consider multiple domains of control striving (e.g., social, work; Grob et al., 1999; Shane \& Heckhausen, 2016). Research on primary and secondary control capacity and striving generally suggests that secondary control capacity increases, while primary control capacity increases, plateaus, and then declines with age. As such, secondary control striving thus "fills in" more for primary control striving across the lifespan in those domains where primary control has decreased (Heckhausen et al., 2010). However, developmental self-regulation is fundamentally context dependent, and it is thus subject to intraindividual differences that interact with environmental opportunities and constraints—such as "actual" and perceived control—over time and across domains.

\section{A Work-Focused Lifespan Control Framework}

Despite the necessary constraints of this review, it is hopefully apparent that the concepts of age, control, and work are inextricable — as well as diffusely and profusely studied. Control is considered and observed to be "good" for employee performance and well-being across the lifespan, and it exists in multiple forms related to individuals, contexts, perceptions, and actions. 
Yet even with these generalities established, gaps in our knowledge remain, and our research corpus lacks organization. With so many control-relevant theories and constructs to choose from, it can be difficult to identify what aspects of control are relevant to study (and when), among whom and how these phenomena should be studied, and where a given study's findings "fit" within the broader landscape of work across the lifespan. To this end, we present an organizing framework of the constructs, attributes, and applications to core age and aging issues at work discussed herein (see Figure 1 and Table 1). We hope this can guide how future scholars conceptualize, contextualize, and differentiate various forms of control. This framework is structured in parallel with the review contents, presenting types of "actual," perceived, and enacted control as distinct but related aspects of the overall concept of control. Central questions, definitions, theories, and citations for each control category and construct (as well as some related but distinct control concepts) are provided alongside pressing age and aging concerns and questions to aid in both research planning and reviewing. Specifically, we see this as a way of adding direction and focus to how and where we study control in relation to age and work, positioning research in certain areas of work and aging to align with particular control categories, constructs, and theories. Our framework, in addition to the concepts and tables discussed next, should help bridge the conceptual, empirical, and pragmatic disconnects noted earlier, highlighting readily addressable, synergetic, and impactful paradigms for studying age, control, and work.

We have a few specific recommendations for aging and work researchers in interpreting and using this framework, particularly in the service of innovative and integrative scholarship (see Table 2). First, we recommend that researchers dig deeper into foundational theory for each category and form of control when designing their studies and hypotheses. Although not every 
control-relevant theory could possibly be covered herein, the sample provided should provide a starting point for such efforts. We do not need new theory, but rather more attention to and testing of existing theory, across studies of age, control, and work. This will contribute greatly to the clarification of how time and development relate to control, functioning, and work, both in terms of hypothesis development (e.g., outlining expected age-based contingencies) and study design (e.g., longitudinal investigations and selection of time lags; Rauvola et al., 2021). Returning to original theory, construct definitions, and intentions - that is, to whom, where, and when the theory was intended to apply, and what it was intended to explain — can also help us create better measures of and measurement approaches for studying control phenomena at different levels. This applies to both intra- and interindividual research as well as the consideration of different organizational units and collective phenomena relevant to age and work.

Second, and relatedly, we recommend that researchers consider the central questions and key age and aging issues provided in this framework when identifying and selecting pertinent constructs for their studies of age and work. Although this is a seemingly "obvious" point, there are subtle but important nuances between, for example, expectancy and self-efficacy: their role in theoretical models and empirical phenomena should differ — and be outlined explicitly—as a result. Clarifying why certain forms of control are or are not pertinent for a study will be important for advancing this area of the literature. This will also require the adoption of consistent terminology, as well as more concerted efforts to describe and justify what type(s) of control are being studied (e.g., "actual” vs. perceived job control). The present framework should provide a starting point for recommended terminology, conceptual attributes, and theory to consider moving forward. 
Third, and to this point, we recommend researchers use this framework to question (control-based) assumptions in their own research and that of others'. Over time, the ubiquity and legacy of psychological constructs can lead to productive adaptation and knowledge generation. However, these forces can also distort fundamental definitions, propositions, and mechanisms, all the while accumulating decades of repetition and citation (an academic form of the children's game "telephone," so to say). This is not to say that the wealth of research considering control does so uncritically. Still, we must maintain a healthy skepticism and vigilance in assessing a) whether studies represent both past and novel findings accurately, and b) where studies meaningfully inform, extend, or contradict our relatively accepted beliefs about age, control, and work (e.g., control's universal benefits). Whether during peer review, literature searches, or data interpretation, we hope this framework provides individuals with tools for appraising research contributions.

Finally, we recommend that researchers approach studies of control with a more holistic and integrative spirit. While we do not suggest that researchers should study all of the control phenomena discussed in this review simultaneously, more research is needed that considers multiple categories of control ("actual," perceived, and enacted) as they intersect with one another and with age and work. Rather than studying these control categories in isolation, we hope that our framework and review can prompt researchers to conduct studies with multiple categories represented and consider how (in)congruence between or change in one form of control can impact other forms. As the workforce ages and grows increasingly diverse, research attention must turn toward supporting the health and performance of employees from all backgrounds and not just those from relatively privileged backgrounds. We believe one way to do this is by studying control from objective, perceptual, and self-regulatory perspectives. By 
considering the external, internal, personal, and structural, we can better understand who ages successfully and how to better and broadly support aging workers.

\section{Proposed Research Agenda for Age, Control, and Work}

In line with this framework and the areas of confusion or ambiguity highlighted in our review, some key topics warrant research attention (see Table 3). We discuss these broader agenda items in detail next, each of which should augment the adoption and impact of the specific age, control, and work applications discussed throughout our review (see also Table 1). The sheer size and scope of the control literature can prove daunting and even unhelpfully fluid and flexible. We hope that the areas we highlighted, based on review findings and areas of theoretical, conceptual, and practical overlap, establish a starting point for addressing the substantial issues in age and work research to come.

First, more work is needed that considers the role of time and timing in control research (e.g., Bohlmann et al., 2018; Rauvola et al., 2021). This includes the need for both concurrent and longitudinal studies of multiple forms of control, both of which would help address questions about a) development, stability, and change in forms of "actual," perceived, and enacted control, b) the trajectories of and relative contributions of different forms of control to functioning, and c) how control intersects with aging, as opposed to focusing on age as a moderator of control's effects on well-being outcomes. Although determining how age (among other factors) may moderate the generally agreed-upon "goodness" of control (i.e., for functioning across the lifespan) is useful, future researchers should take more explicit time- and development-oriented approaches to studying control at work. Relatedly, research is needed that centers around and/or differentiates between past, present, and prospective forms of control: that is, control attributions at different "stages" of control striving processes may contribute to and 
shape other forms of control and related outcomes. The concept of "experiences of control" (Skinner, 1996, p. 551) is worth exploring in thinking about different forms of control, especially across time, as are the distinctions made herein regarding control predictions, appraisals, and attributions (e.g., expectancy vs. self-efficacy, locus of control) and their applications for ageand age-related issues at work.

To this end, cross-domain considerations will be important to leverage, as the study of aging and lifespan development necessarily occurs in diverse, multiperson and multidomain (e.g., work, family, school, local community) environments. Work in this vein would benefit from multidisciplinary involvement, such as research collaborations to integrate sociological perspectives on the life course (e.g., Elder, 1994; Salmela-Aro, 2009), life domain influences, and social identities. Studying experienced (mis)fit in forms of control, control experiences, and attributions within and across various life domains could help uncover how different areas of control relate and how they can compensate for, or come at the detriment of, one another. Some work on control (in)congruence has been conducted thus far (e.g., between perceived and enacted control; Grümer et al., 2013; Shane \& Heckhausen, 2012, 2016), and more work-focused studies that account for additional categories and forms of control are needed.

Control-related fit in organizations, particularly as they pertain to "actual" controlrelevant personal and contextual factors, will also require work to integrate traditional control perspectives with theories of organizational control. This aligns with Sitkin and colleagues' (2020) recent call for confluence between macro and "control recipient" perspectives (Sitkin et al., 2020) as well as Kooij and colleagues' (2020) multilevel model of successful aging at work (Kooij et al., 2020; see also Kellogg et al., 2020; Rauvola \& Rudolph, 2020). Greater knowledge about the experience of control within organizations, and its implications for the aging 
workforce, will aid in developing and implementing practical and inclusive interventions and policies.

Finally, and pertaining to fit and contexts, we recommend more research into the cultural components of control. Specifically, work could investigate the ways that different geographic and ideological landscapes may influence the benefits and drawbacks of different forms of control, or even individuals' perceived need for control (e.g., control orientations, see Yamaguchi, 2001). Control, empowerment, and autonomy hold not only biological and psychological significance, but also cultural and political significance. This warrants greater theoretical and empirical attention, placing more focus on the "social" aspect of biopsychosocial models of functioning and development for the aging and diverse workforce.

\section{Conclusion}

There is a wealth of research on control (particularly relevant to age and work) as well as both general and specific areas to address in order to move work and aging theory, research, and practice forward. This paper sought to review and synthesize a variety of control constructs relevant to age and work, provide an organizing framework to aid in theoretical revision and research, and generate a research agenda to direct work focused on control and the age-diverse workforce. The concept of control is central to psychological research, and to the maintenance of performance and well-being at work across the lifespan. However, conceptual complexities and inconsistencies pose challenges to studying control, and thereby to developing and implementing effective control-relevant organizational practices. Our review sought to highlight these issues, guiding scholars interested in control and aging at work toward aspects of the literature to which they can impactfully contribute. 


\section{References}

Abraham, J. D., \& Hansson, R. O. (1996). Gender differences in the usefulness of goal-directed coping for middle-aged and older workers. Journal of Applied Social Psychology, 26, 657-669. doi:10.1111/j.1559-1816.1996.tb02737.x

Abramson, L. Y., Seligman, M. E. P., \& Teasdale, J. D. (1978). Learned helplessness in humans. Journal of Abnormal Psychology, 87, 49-74. doi:10.1037/0021-843x.87.1.49

Adams, J. S. (1965). Inequity in social exchange. In L. Berkowitz (Ed.), Advances in experimental social psychology (vol. 2, pp. 267-299). doi:10.1016/s00652601(08)60108-2

Ajzen, I. (1991). The theory of planned behavior. Organizational Behavior and Human Decision Processes, 50, 179-211. doi:10.1016/0749-5978(91)90020-T

Ajzen, I. (2002). Perceived behavioral control, self-efficacy, locus of control, and the theory of planned behavior. Journal of Applied Social Psychology, 32, 665-683. doi:10.1111/j.1559-1816.2002.tb00236.x

Alarcon, G., Eschleman, K. J., \& Bowling, N. A. (2009). Relationships between personality variables and burnout: A meta-analysis. Work \& Stress, 23, 244-263. doi:10.1080/02678370903282600

Alcover, C. M., Guglielmi, D., Depolo, M., \& Mazzetti, G. (2021). “Aging-and-Tech Job Vulnerability": A proposed framework on the dual impact of aging and AI, robotics, and automation among older workers. Organizational Psychology Review. doi:10.1177/2041386621992105

Aldwin, C. M., Skinner, E. A., Zimmer-Gembeck, M. J., \& Taylor, A. (2011). Coping and self- 
regulation across the lifespan. In K. L. Fingerman, J. Smith, C. Berg, \& T. C. Antonucci (Eds.), Handbook of life-span development (pp. 561-587). New York, NY, US: Springer.

Alfredsson, L., Karasek, R., \& Theorell, T. (1982). Myocardial infarction risk and psychosocial work environment: An analysis of the male Swedish working force. Social Science \& Medicine, 16, 463-467. doi:10.1016/0277-9536(82)90054-5

Alvesson, M., \& Sandberg, J. (2020). The problematizing review: A counterpoint to Elsbach and Van Knippenberg's argument for integrative reviews. Journal of Management Studies, 57, 1290-1304. doi:10.1111/joms.12582

Antonovski, A. (1987). Unraveling the mystery of health: How people manage stress and stay well. San Francisco, CA, US: Jossey-Bass.

Atkinson, J. W. (1957). Motivational determinants of risk-taking behavior. Psychological Review, 64, 359-372. doi:10.1037/h0043445

Atkinson, J. W., \& Birch, D. (1970). The dynamics of action. New York, NY, US: Wiley.

Averill, J. R. (1973). Personal control over aversive stimuli and its relationship to stress. Psychological Bulletin, 80, 286-303. doi:10.1037/h0034845

Bailly, N., Gana, K., Hervé, C., Joulain, M., \& Alaphilippe, D. (2014). Does flexible goal adjustment predict life satisfaction in older adults? A six-year longitudinal study. Aging \& Mental Health, 18, 662-670. doi:10.1080/13607863.2013.875121

Bajor, J. K., \& Baltes, B. B. (2003). The relationship between selection optimization with compensation, conscientiousness, motivation, and performance. Journal of Vocational Behavior, 63, 347-367. doi:10.1016/S0001-8791(02)00035-0

Bakker, A. B., \& Demerouti, E. (2017). Job demands-resources theory: Taking stock and 
looking forward. Journal of Occupational Health Psychology, 22, 273-285. doi:10.1037/ocp0000056

Baltes, P. B. (1987). Theoretical propositions of life-span developmental psychology: On the dynamics between growth and decline. Developmental Psychology, 23, 611-626. doi:10.1037/0012-1649.23.5.611

Baltes, P. B., \& Baltes, M. M. (1990). Psychological perspectives on successful aging: The model of selective optimization with compensation. In P. B. Baltes \& M. M. Baltes (Eds.), Successful aging: Perspectives from the behavioral sciences (pp. 1-34). New York, NY, US: Cambridge University Press.

Bandura, A. (1977a). Self-efficacy: Toward a unifying theory of behavioral change. Psychological Review, 84, 191-215. doi:10.1037/0033-295x.84.2.191

Bandura, A. (1977b). Social learning theory. Englewood Cliffs, NJ: Prentice-Hall.

Bandura, A. (1982). Self-efficacy mechanism in human agency. American Psychologist, 37, 122-147. doi:10.1037/0003-066x.37.2.122

Bandura, A. (1986). Social foundations of thought and action: A social cognitive theory. Englewood Cliffs, NJ: Prentice-Hall.

Bandura, A. (1997). Theoretical perspectives. In A. Bandura (Ed.), Self-efficacy: The exercise of control (pp. 1-35). New York, NY, US: Freeman.

Bandura, A. (1998). Health promotion from the perspective of social cognitive theory. Psychology and Health, 13, 623-649. doi:10.1080/08870449808407422

Bandura, A. (2001). Social cognitive theory: An agentic perspective. Annual Review of Psychology, 52, 1-26. doi:10.1146/annurev.psych.52.1.1

Bandura, A. (2006). Guide for constructing self-efficacy scales. In F. Pajares \& T. Urdan (Eds.), 
Self-efficacy beliefs of adolescents (pp. 307-337). Greenwich, CT: Information Age Publishing.

Barrick, M. R., Mount, M. K., \& Li, N. (2013). The theory of purposeful work behavior: The role of personality, higher-order goals, and job characteristics. Academy of Management Review, 38, 132-153. doi:10.5465/amr.10.0479

Bartol, K. M. (1976). Expectancy theory as a predictor of female occupational choice and attitude toward business. The Academy of Management Journal, 19, 669-675. doi:10.2307/255801

Besen, E., Matz-Costa, C., James, J. B., \& Pitt-Catsouphes, M. (2015). Factors buffering against the effects of job demands: How does age matter? Journal of Applied Gerontology, 34, 73-101. doi:10.1177/0733464812460430

Best, R. G., Stapleton, L. M., \& Downey, R. G. (2005). Core self-evaluations and job burnout: the test of alternative models. Journal of Occupational Health Psychology, 10, 441-451. doi:10.1037/1076-8998.10.4.441

Bohlmann, C., Rudolph, C. W., \& Zacher, H. (2018). Methodological recommendations to move research on work and aging forward. Work, Aging and Retirement, 4, 225-237. doi:10.1093/workar/wax023

Boyar, S. L., \& Mosley, D. C., Jr. (2007). The relationship between core self-evaluations and work and family satisfaction: The mediating role of work-family conflict and facilitation. Journal of Vocational Behavior, 71, 265-281. doi:10.1016/j.jvb.2007.06.001

Brandstädter, J., \& Renner, G. (1990). Tenacious goal pursuit and flexible goal adjustment: Explication and age-related analysis of assimilative and accommodative strategies of coping. Psychology and Aging, 5, 58-67. doi:10.1037/0882-7974.5.1.58 
Brandtstädter, J., \& Rothermund, K. (1994). Self-percepts of control in middle and later adulthood: Buffering losses by rescaling goals. Psychology and Aging, 9, 265-273. doi:10.1037/0882-7974.9.2.265

Breslin, D., \& Gatrell, C. (2020). Theorizing through literature reviews: The miner-prospector continuum. Organizational Research Methods. doi:10.1177/1094428120943288

Broadbent, J., de Quadros-Wander, S., \& McGillivray, J. A. (2014). Perceived control's influence on wellbeing in residential care versus community dwelling older adults. Journal of Happiness Studies, 15, 845-855. doi:10.1007/s10902-013-9452-9

Brooks, L., \& Betz, N. E. (1990). Utility of expectancy theory in predicting occupational choices in college students. Journal of Counseling Psychology, 37, 57-64. doi:10.1037/00220167.37.1.57

Breaugh, J. A. (1985). The measure of work autonomy. Human Relations, 38, 551-570. doi:10.1177/001872678503800604

Breaugh, J. A. (1998). The development of a new measure of global work autonomy. Educational and Psychological Measurement, 58, 119-128. doi:10.1177/0013164498058001010

Breaugh, J. A. (1999). Further investigation of the work autonomy scales: Two studies. Journal of Business and Psychology, 13, 357-373. doi:10.1023/a:1022926416628

Carstensen, L. L., Isaacowitz, D. M., \& Charles, S. T. (1999). Taking time seriously: A theory of socioemotional selectivity. American Psychologist, 54, 165-181. doi:10.1037/0003066x.54.3.165

Chanowitz, B., \& Langer, E. (1980). Knowing more (or less) than you can show: Understanding 
control through the mindlessness-mindfulness distinction. In J. Garber \& M. E. P. Seligman (Eds.), Human helplessness: Theory and applications (pp. 97-129). New York, NY, US: Academic Press.

Charles, S. T. (2010). Strength and vulnerability integration (SAVI): A model of emotional wellbeing across adulthood. Psychological Bulletin, 136, 1068-1091. doi:10.1037/a0021232

Chen, S., Westman, M., \& Eden, D. (2009). Impact of enhanced resources on anticipatory stress and adjustment to new information technology: A field-experimental test of conservation of resources theory. Journal of Occupational Health Psychology, 14, 219-230. doi:10.1037/a0015282

Chesnut, S. R., \& Burley, H. (2015). Self-efficacy as a predictor of commitment to the teaching profession: A meta-analysis. Educational Research Review, 15, 1-16. doi:10.1016/j.edurev.2015.02.001

Chiesa, R., Toderi, S., Dordoni, P., Henkens, K., Fiabane, E. M., \& Setti, I. (2016). Older workers: Stereotypes and occupational self-efficacy. Journal of Managerial Psychology, 31, 1152-1166. doi:10.1108/jmp-11-2015-0390

Chipperfield, J. G., Hamm, J. M., Perry, R. P., \& Ruthig, J. C. (2017). Perspectives on studying perceived control in the twenty-first century. In M. D. Robinson \& M. Eid (Eds.), The happy mind: Cognitive contributions to well-being (pp. 215-233). doi:10.1007/978-3319-58763-9_12

Chiu, C.-Y., Hong, Y.-Y., \& Dweck, C. S. (1997). Lay dispositionism and implicit theories of personality. Journal of Personality and Social Psychology, 73, 19-30. doi:10.1037/00223514.73.1.19

Colquitt, J. A., Conlon, D. E., Wesson, M. J., Porter, C. O. L. H., \& Ng, K. Y. (2001). Justice at 
the millennium: A meta-analytic review of 25 years of organizational justice research. Journal of Applied Psychology, 86, 425-445. doi:10.1037/0021-9010.86.3.425

Daniels, K., Glover, J., Nayani, R., Mellor, N., \& Munir, F. (2018). Purpose and enactment in job design: An empirical examination of the process through which job characteristics have their effects. Policy and Practice in Health and Safety, 16, 20-42.

doi:10.1080/14773996.2017.1376833

Daniels, K., \& Guppy, A. (1994). Occupational stress, social support, job control, and psychological well-being. Human Relations, 47, 1523-1544.

doi:10.1177/001872679404701205

Deci, E. L., \& Ryan, R. M. (1985a). The general causality orientations scale: Self-determination in personality. Journal of Research in Personality, 19, 109-134. doi:10.1016/00926566(85)90023-6

Deci, E. L., \& Ryan, R. M. (1985b). The general causality orientations scale: Self-determination in personality. Journal of Research in Personality, 19, 109-134. doi:10.1016/00926566(85)90023-6

Degelman, D., Owens, S. A. A., Reynolds, T., \& Riggs, J. (1991). Age and gender differences in beliefs about personal power and injustice. The International Journal of Aging and Human Development, 33, 101-111. doi:10.2190/qtwj-wrb9-f3ch-btkx

De Jonge, J. (1995). Job autonomy, well-being, and health: A study among Dutch health care workers. (Unpublished doctoral dissertation). Datawyse, Maastricht, Netherlands.

De Jonge, J., van Breukelen, G. J. P., Landeweerd, J. A., \& Nijhuis, F. J. N. (1999). Comparing 
group and individual level assessments of job characteristics in testing the job demandcontrol model: A multilevel approach. Human Relations, 52, 95-122. doi:10.1177/001872679905200106

de Lange, A. H., Taris, T. W., Kompier, M. A. J., Houtman, I. L. D., \& Bongers, P. M. (2003). "The very best of the millennium": Longitudinal research and the demand-control(support) model. Journal of Occupational Health Psychology, 8, 282-305. doi:10.1037/1076-8998.8.4.282

Demerouti, E., Bakker, A. B., Nachreiner, F., \& Schaufeli, W. B. (2001). The job demandsresources model of burnout. Journal of Applied Psychology, 86, 499-512. doi:10.1037/0021-9010.86.3.499

Deutsch, M. (1975). Equity, equality, and need: What determines which value will be used as the basis of distributive justice? Journal of Social Issues, 31, 137-150. doi:10.1111/j.15404560.1975.tb01000.x

de Quadros-Wander, S., McGillivray, J., \& Broadbent, J. (2014). The influence of perceived control on subjective wellbeing in later life. Social Indicators Research, 115, 999-1010. doi:10.1007/s11205-013-0243-9

de Rijk, A. E., Le Blanc, P. M., Schaufeli, W. B., \& De Jonge, J. (1998). Active coping and need for control as moderators of the job demand-control model: Effects on burnout. Journal of Occupational and Organizational Psychology, 71, 1-18. doi:10.1111/j.20448325.1998.tb00658.x

Dixon, M. L., \& Hart, L. K. (2010). The impact of path-goal leadership styles on work group effectiveness and turnover intention. Journal of Managerial Issues, 22, 52-69.

Doerwald, F., Zacher, H., van Yperen, N. W., \& Scheibe, S. (2020). Generativity at work: A 
meta-analysis. Journal of Vocational Behavior. doi:10.1016/j.jvb.2020.103521

Dweck, C. S., Chiu, C. Y., \& Hong, Y. Y. (1995). Implicit theories and their role in judgments and reactions: A word from two perspectives. Psychological Inquiry, 6, 267-285. doi:10.1207/s15327965pli0604_1

Dweck, C. S., \& Leggett, E. L. (1988). A social-cognitive approach to motivation and personality. Psychological Review, 95, 256-273. doi:10.1037/0033-295x.95.2.256

Elder, G. H., Jr. (1994). Time, human agency, and social change: Perspectives on the life course. Social Psychology Quarterly, 57, 4-15. doi:10.2307/2786971

Ellis, A. M., Bauer, T. N., \& Erdogan, B. (2015). New-employee organizational socialization: Adjusting to new roles, colleagues, and organizations. In J. E. Grusec \& P. D. Hastings (Eds.), Handbook of socialization: Theory and research (2nd ed., pp. 301-322). New York, NY, US: Guilford Press.

Elsass, P. M., \& Veiga, J. F. (1997). Job control and job strain: A test of three models. Journal of Occupational Health Psychology, 2, 195-211. doi:10.1037/1076-8998.2.3.195

Erez, A., \& Isen, A. M. (2002). The influence of positive affect on the components of expectancy motivation. Journal of Applied Psychology, 87, 1055-1067. doi:10.1037/00219010.87.6.1055

Erez, A., \& Judge, T. A. (2001). Relationship of core self-evaluations to goal setting, motivation, and performance. Journal of Applied Psychology, 86, 1270-1279. doi:10.1037/00219010.86 .6 .1270

Elsbach, K. D., \& van Knippenberg, D. (2020). Creating high-impact literature reviews: An argument for 'integrative reviews'. Journal of Management Studies, 57, 1277-1289. doi:10.1111/joms.12581 
Fila, M. J. (2016). The job demands, control, support model: Where are we now? TKM International Journal for Research in Management, 1, 15-44.

Fila, M. J., Purl, J., \& Griffeth, R. W. (2017). Job demands, control and support: Meta-analyzing moderator effects of gender, nationality, and occupation. Human Resource Management, 27, 39-60. doi:10.1016/j.hrmr.2016.09.004

Fishbein, M., \& Ajzen, I. (1975). Belief, attitude, intention and behavior: An introduction to theory and research. Reading, MA: Addison-Wesley.

Flammer, A. (1997). Developmental analysis of control beliefs. In A. Bandura (Ed.), Selfefficacy in changing societies (pp. 69-113). doi:10.1017/cbo9780511527692.005

Folkman, S., Lazarus, R. S., Dunkel-Schetter, C., DeLongis, A., \& Gruen, R. J. (1986). Dynamics of a stressful encounter: Cognitive appraisal, coping, and encounter outcomes. Journal of Personality and Social Psychology, 50, 992-1003. doi:10.1037/00223514.50.5.992

Ford, M. T., \& Wooldridge, J. D. (2012). Industry growth, work role characteristics, and job satisfaction: A cross-level mediation model. Journal of Occupational Health Psychology, 17, 492-504. doi:10.1037/a0029535

Fox, M. L., Dwyer, D. J., \& Ganster, D. C. (1993). Effects of stressful job demands and control on physiological and attitudinal outcomes in a hospital setting. Academy of Management Journal, 36, 289-318. doi:10.2307/256524

Furnham, A., \& Steele, H. (1993). Measuring locus of control: A critique of general, children's, health-and work-related locus of control questionnaires. British Journal of Psychology, 84, 443-479. doi:10.1111/j.2044-8295.1993.tb02495.x

Frese, M., \& Sabini, J. (Eds.). (1985). Goal directed behavior: The concept of action in 
psychology. Hillsdale, NJ, US: Erlbaum.

Frese, M., \& Zapf, D. (1994). Action as the core of work psychology: A German approach. In H. C. Triandis, M. D. Dunne e \& L. Hough (Eds.), Handbook of industrial and organizational psychology (vol. 4, pp. 271-340). Palo Alto, CA, US: Consulting Psychologists Press.

Freund, A. M., \& Baltes, P. B. (2000). The orchestration of selection, optimization and compensation: An action-theoretical conceptualization of a theory of developmental regulation. In W. J. Perrig \& A. Grob (Eds.), Control of human behavior, mental processes, and consciousness (pp. 35-58). Mahwah, NJ: Erlbaum.

Fried, Y., \& Ferris, G. R. (1987). The validity of the job characteristics model: A review and meta-analysis. Personnel Psychology, 40, 287-322. doi:10.1111/j.17446570.1987.tb00605.x

Fusilier, M. R., Ganster, D. C., \& Mayes, B. T. (1987). Effects of social support, role stress, and locus of control on health. Journal of Management, 13, 517-528. doi:10.1177/014920638701300308

Ganster, D. C. (1989). Measurement of worker control. Final report to the National Institute of Occupational Safety and Health, Contract No. 88-791.

Ganster, D. (2011). Autonomy and control. ILO Encyclopaedia of Occupational Health \& Safety. Retrieved from http://www.iloencyclopaedia.org/component/k2/59-factorsintrinsic-to-the-job/autonomy-and-control

Ganster, D. C., \& Fusilier, M. R. (1989). Control in the workplace. International Review of Industrial and Organizational Psychology, 4, 235-280.

Ganster, D. C., \& Schaubroeck, J. (1991). Work stress and employee health. Journal of 
Management, 17, 235-271. doi:10.1177/014920639101700202

Gärtner, L. U., \& Hertel, G. (2020). Age as moderator of the relationship between self-efficacy and effort in occupational teams. Work, Aging and Retirement, 6, 118-129. doi:10.1093/workar/waz024

Gärtner, L. U., Nohe, C., \& Hertel, G. (2019). Lifespan perspectives on individuals’ effort in work teams. In B. B. Baltes, C. W. Rudolph, \& H. Zacher (Eds.), Work across the lifespan (pp. 437-454). doi:10.1016/B978-0-12-812756-8.00018-9

Gatz, M., Siegler, I. C., George, L. K., \& Tyler, F. B. (1986). Attributional components of locus of control: Longitudinal, retrospective, and contemporaneous analyses. In M. M. Baltes \& P. B. Baltes (Eds.), The psychology of control and aging (pp. 237-263). Hillsdale, NJ, US: Lawrence Erlbaum.

Gaudreau, P., Carraro, N., \& Miranda, D. (2012). From goal motivation to goal progress: The mediating role of coping in the self-concordance model. Anxiety, Stress \& Coping, 25, 507-528. doi:10.1080/10615806.2011.628015

Georgopoulos, B. S., Mahoney, G. M., \& Jones, N. W., Jr. (1957). A path-goal approach to productivity. Journal of Applied Psychology, 41, 345-353. doi:10.1037/h0048473

Gignac, M. A., Kristman, V., Smith, P. M., Beaton, D. E., Badley, E. M., Ibrahim, S., \& Mustard, C. A. (2018). Are there differences in workplace accommodation needs, use and unmet needs among older workers with arthritis, diabetes and no chronic conditions? Examining the role of health and work context. Work, Aging and Retirement, 4, 381-398. doi:10.1093/workar/way004

Gist, M. E. (1987). Self-efficacy: Implications for organizational behavior and human resource 
management. The Academy of Management Review, 12, 472-485.

doi:10.5465/amr.1987.4306562

Gist, M. E., \& Mitchell, T. R. (1992). Self-efficacy: A theoretical analysis of its determinants and malleability. Academy of Management Review, 17, 183-211.

doi:10.5465/amr.1992.4279530

Glass, D. C., McKnight, J. D., \& Valdimarsdottir, H. (1993). Depression, burnout, and perceptions of control in hospital nurses. Journal of Counseling and Clinical Psychology, 61, 147-155. doi:10.1037/0022-006X.61.1.147

Goossens, M. E., Kindermans, H. P., Morley, S. J., Roelofs, J., Verbunt, J., \& Vlaeyen, J. W. (2010). Self-discrepancies in work-related upper extremity pain: Relation to emotions and flexible-goal adjustment. European Journal of Pain, 14, 764-770. doi:10.1016/j.ejpain.2009.11.012

Graen, G. (1969). Instrumentality theory of work motivation: Some experimental results and suggested modifications. Journal of Applied Psychology, 53, 1-25. doi: $10.1037 / \mathrm{h} 0027100$

Grau, R., Salanova, M., \& Peiró, J. M. (2001). Moderator effects of self-efficacy on occupational stress. Psychology in Spain, 5, 63-74.

Greenberg, J. (1987). A taxonomy of organizational justice theories. Academy of Management Review, 12, 9-22. doi:10.5465/amr.1987.4306437

Grob, A., Little, T. D., \& Wanner, B. (1999). Control judgements across the lifespan. International Journal of Behavioral Development, 23, 833-854. doi:10.1080/016502599383568

Grümer, S., Silbereisen, R. K., \& Heckhausen, J. (2013). Subjective well-being in times of social 
change: Congruence of control strategies and perceived control. International Journal of Psychology, 48, 1267-1283. doi:10.1080/00207594.2012.744839

Hackman, J. R., \& Oldham, G. R. (1974). The job diagnostic survey: An instrument for the diagnosis of jobs and the evaluation of job redesign projects. Department of Administrative Sciences: Yale University.

Hackman, J. R., \& Oldham, G. R. (1975). Development of the job diagnostic survey. Journal of Applied Psychology, 60, 159-170. doi:10.1037/h0076546

Hajek, A., \& König, H. H. (2017). The role of flexible goal adjustment in the effect of informal caregiving on depressive symptoms: Evidence of a large population-based longitudinal study in Germany from 2002 to 2011. Quality of Life Research, 26, 419-427. doi:10.1007/s11136-016-1399-y

Halbesleben, J. R. B. (2006). Sources of social support and burnout: A meta-analytic test of the conservation of resources model. Journal of Applied Psychology, 91, 1134-1145. doi:10.1037/0021-9010.91.5.1134

Hale, W. D., \& Cochran, C. D. (1986). Locus of control across the adult lifespan. Psychological Reports, 59, 311-313. doi:10.2466/pr0.1986.59.1.311

Hamm, J. M., Chipperfield, J. G., Perry, R. P., Parker, P. C., \& Heckhausen, J. (2017). Tenacious self-reliance in health maintenance may jeopardize late life survival. Psychology and Aging, 32, 628-635. doi:10.1037/pag0000201

Hauff, S., Richter, N. F., \& Tressin, T. (2015). Situational job characteristics and job satisfaction: The moderating role of national culture. International Business Review, 24, 710-723. doi:10.1016/j.ibusrev.2015.01.003

Häusser, J. A., Mojzisch, A., Niesel, M., \& Schulz-Hardt, S. (2010). Ten years on: A review of 
recent research on the job demand-control (-support) model and psychological wellbeing. Work \& Stress, 24, 1-35. doi:10.1080/02678371003683747

Haynes, T. L., Heckhausen, J., Chipperfield, J. G., Perry, R. P., \& Newall, N. E. (2009). Primary and secondary control strategies: Implications for health and well-being among older adults. Journal of Social and Clinical Psychology, 28, 165-197.

doi:10.1521/jscp.2009.28.2.165x

Heckhausen, J., \& Schulz, R. (1995). A life-span theory of control. Psychological Review, 102, 284-304. doi:10.1037/0033-295x.102.2.284

Heckhausen, J., \& Schulz, R. (1999b). The primacy of primary control is a human universal: A reply to Gould's (1999) critique of the life-span theory of control. Psychological Review, 106, 605-609. doi:10.1037/0033-295x.106.3.605

Heckhausen, J., Wrosch, C., \& Schulz, R. (2010). A motivational theory of life-span development. Psychological Review, 117, 32-60. doi:10.1037/a0017668

Heckhausen, J., Wrosch, C., \& Schulz, R. (2019). Agency and motivation in adulthood and old age. Annual Review of Psychology, 70, 191-217. doi:10.1146/annurev-psych-010418103043

Heraty, N., \& McCarthy, J. (2015). Unearthing psychological predictors of financial planning for retirement among late career older workers: Do self-perceptions of aging matter? Work, Aging and Retirement, 1, 274-283. doi:10.1093/workar/wav008

Hertel, G., Rauschenbach, C., Thielgen, M. M., \& Krumm, S. (2015). Are older workers more active copers? Longitudinal effects of age-contingent coping on strain at work. Journal of Organizational Behavior, 36, 514-537. doi:10.1002/job.1995

Hertel, G., Thielgen, M., Rauschenbach, C., Grube, A., Stamov- Roßnagel, C., \& Krumm, S. 
(2013). Age differences in motivation and stress at work. In C. M. Schlick, E. Frieling, \& J. Wegge (Eds.), Age-differentiated work systems (pp. 119-147). doi:10.1007/978-3-64235057-3_6

Herzberg, F., Mausner, B., \& Synderman, B. (1959). The motivation to work. New York, NY, US: Wiley.

Heyl, V., Wahl, H.-W., \& Mollenkopft, H. (2007). Affective well-being in old age: The role of tenacious goal pursuit and flexible goal adjustment. European Psychologist, 12, 119-129. doi:10.1027/1016-9040.12.2.119

Hobfoll, S. E. (1989). Conservation of resources: A new attempt at conceptualizing stress. American Psychologist, 44, 513-524. doi:10.1037/0003-066x.44.3.513

Hobfoll, S. E. (2001). The influence of culture, community, and the nested-self in the stress process: Advancing conservation of resources theory. Applied Psychology, 50, 337-421. doi:10.1111/1464-0597.00062

Hobfoll, S. E., \& Wells, J. D. (1998). Conservation of resources, stress, and aging: Why do some slide and some spring? In J. Lomranz (Ed.), Handbook of aging and mental health (pp. 121-134). doi:10.1007/978-1-4899-0098-2_6

Hockey, G. R. J. (1993). Cognitive-energetical control mechanisms in the management of work demands and psychological health. In A. Baddely \& L. Weiskrantz (Eds.), Attention: selection, awareness, and control (pp. 328-345). Oxford, UK: Clarendon Press.

Holladay, C. L., \& Quiñones, M. A. (2003). Practice variability and transfer of training: The role of self-efficacy generality. Journal of Applied Psychology, 88, 1094-1103. doi:10.1037/0021-9010.88.6.1094

Hoppmann, C. A., \& Klumb, P. L. (2012). Daily management of work and family goals in 
employed parents. Journal of Vocational Behavior, 81, 191-198.

doi:10.1016/j.jvb.2012.07.001

Houkes, I., Janssen, P. P. M., de Jonge, J., \& Bakker, A. B. (2003). Personality, work characteristics, and employee well-being: A longitudinal analysis of additive and moderating effects. Journal of Occupational Health Psychology, 8, 20-38.

doi:10.1037/1076-8998.8.1.20

House, R. J. (1977). A 1976 theory of charismatic leadership. In J. G. Hunt \& L. L. Larson (Eds), Leadership: The cutting edge (pp. 189-207). Carbondale, IL, US: Southern Illinois University Press.

House, R. J. (1996). Path-goal theory of leadership: Lessons, legacy, and a reformulated theory. The Leadership Quarterly, 7, 323-352. doi:10.1016/S1048-9843(96)90024-7

House, R. J., \& Mitchell, T. R. (1975). Path-goal theory of leadership (No. TR-75-67). University of Washington Department of Psychology.

Huffman, A., Culbertson, S. S., Henning, J. B., \& Goh, A. (2013). Work-family conflict across the lifespan. Journal of Managerial Psychology, 28, 761-780. doi:10.1108/JMP-072013-0220

Humphrey, S. E., Nahrgang, J. D., \& Morgeson, F. P. (2007). Integrating motivational, social, and contextual work design features: A meta-analytic summary and theoretical extension of the work design literature. Journal of Applied Psychology, 92, 1332-1356. doi:10.1037/0021-9010.92.5.1332

Ilgen, D. R., Nebeker, D. M., \& Pritchard, R. D. (1981). Expectancy theory measures: AN empirical comparison in an experimental simulation. Organizational Behavior and Human Performance, 28, 189-223. doi:10.1016/0030-5073(81)90022-2 
Johnson, J. V., \& Hall, E. M. (1988). Job strain, work place social support, and cardiovascular health: A cross-sectional study of a random sample of Swedish working population. American Journal of Public Health, 78, 1336-1342. doi:10.2105/ajph.78.10.1336

Johnson, R. E., Rosen, C. C., Chang, C.-H., \& Lin, S.-H. (2015). Getting to the core of locus of control: Is it an evaluation of the self or the environment? Journal of Applied Psychology, 100, 1568-1578. doi:10.1037/ap10000011

Judge, T. A., \& Bono, J. E. (2001). Relationship of core self-evaluations traits—self-esteem, generalized self-efficacy, locus of control, and emotional stability—with job satisfaction and job performance: A meta-analysis. Journal of Applied Psychology, 86, 80-92. doi:10.1037/0021-9010.86.1.80

Judge, T. A., Bono, J. E., Erez, A., \& Locke, E. A. (2005). Core self-evaluations and job and life satisfaction: The role of self-concordance and goal attainment. Journal of Applied Psychology, 90, 257-268. doi:10.1037/0021-9010.90.2.257

Judge, T. A., Erez, A., \& Bono, J. E. (1998). The power of being positive: The relation between positive self-concept and job performance. Human Performance, 11, 167-187. doi:10.1207/s15327043hup1102\&3_4

Judge, T. A., Erez, A., Bono, J. E., \& Thoresen, C. J. (2002). Are measures of self-esteem, neuroticism, locus of control, and generalized self-efficacy indicators of a common core construct? Journal of Personality and Social Psychology, 83, 693-710. doi:10.1037/0022-3514.83.3.693

Judge, T. A., \& Hurst, C. (2007). Capitalizing on one's advantages: Role of core self-evaluations. Journal of Applied Psychology, 92, 1212-1227. doi:10.1037/0021-9010.92.5.1212

Judge, T. A., Locke, E. A., \& Durham, C. C. (1997). The dispositional causes of job satisfaction: 
A core evaluations approach. Research in Organizational Behavior, 19, 151-188.

Judge, T. A., Locke, E. A., Durham, C. C., \& Kluger, A. N. (1998). Dispositional effects on job and life satisfaction: The role of core evaluations. Journal of Applied Psychology, 83, 1734. doi:10.1037/0021-9010.83.1.17

Judge, T. A., Van Vianen, A. E. M., \& De Pater, I. E. (2004). Emotional stability, core selfevaluations, and job outcomes: A review of the evidence and an agenda for future research. Human Performance, 17, 325-346. doi:10.1207/s15327043hup1703_4

Kacmar, K. M., Collins, B. J., Harris, K. J., \& Judge, T. A. (2009). Core self-evaluations and job performance: The role of the perceived work environment. Journal of Applied Psychology, 94, 1572-1580. doi:10.1037/a0017498

Kain, J., \& Jex, S. (2010). Karasek's (1979) job demands-control model: A summary of current issues and recommendations for future research. In P. L. Perrewé \& D. C. Ganster (Eds.), New developments in theoretical and conceptual approaches to job stress: Research in occupational stress and well-being (vol. 8, pp. 237-268). doi:10.1108/s14793555(2010)0000008009

Kanfer, R. (1990). Motivation theory and industrial and organizational psychology. In M. D. Dunnette \& L Hough (Eds.), Handbook of industrial and organizational psychology, vol. 1: Theory in industrial and organizational psychology (pp. 75-170). Palo Alto, CA: Consulting Psychologists Press.

Kanfer, R., Frese, M., \& Johnson, R. E. (2017). Motivation related to work: A century of progress. Journal of Applied Psychology, 102, 338-355. doi:10.1037/apl0000133

Karasek, R. A., Jr. (1979). Job demands, job decision latitude, and mental strain: Implications for job redesign. Administrative Science Quarterly, 24, 285-230. doi:10.2307/2392498 
Karasek, R. A., Jr. (1985). Job Content Questionnaire and user's guide. doi:10.1037/t03609-000

Karasek, R., \& Theorell, T. (1990). Healthy work: Stress, productivity, and the reconstruction of working life. New York, NY, US: Basic Books.

Keller, A. C., Igic, I., Meier, L. L., Semmer, N. K., Schaubroeck, J. M., Brunner, B., \& Elfering, A. (2016). Testing job typologies and identifying at-risk subpopulations using factor mixture models. Journal of Occupational Health Psychology, 22, 503-518. doi:10.1037/ocp0000038

Kellogg, K. C., Valentine, M. A., \& Christin, A. (2020). Algorithms at work: The new contested terrain of control. Academy of Management Annals, 14, 366-410. doi:10.5465/annals.2018.0174

Kennedy, C. W., Fossum, J. A., \& White, B. J. (1983). An empirical comparison of withinsubjects and between-subjects expectancy theory models. Organizational Behavior and Human Performance, 32, 124-143. doi:10.1016/0030-5073(83)90143-5

Koestner, R., Lekes, N., Powers, T. A., \& Chicoine, E. (2002). Attaining personal goals: Selfconcordance plus implementation intentions equals success. Journal of Personality and Social Psychology, 83, 231-244. doi:10.1037/0022-3514.83.1.231

Kooij, D., de Lange, A., Jansen, P., \& Dikkers, J. (2008). Older workers' motivation to continue to work: Five meanings of age: A conceptual review. Journal of Managerial Psychology, 23, 364-394. doi:10.1108/02683940810869015

Kooij, D. T. A. M., Tims, M., \& Kanfer, R. (2015). Successful aging at work: The role of job crafting. In P. M. Bal, D. T. A. M. Kooij, \& D. Rousseau (Eds.), Aging workers and the employee-employer relationship (pp. 145-161). doi:10.1007/978-3-319-08007-9_9

Kooij, D. T. A. M., Kanfer, R., Betts, M., \& Rudolph, C. W. (2018). Future time perspective: 
A systematic review and meta-analysis. Journal of Applied Psychology, 103, 867-893. doi:10.1037/ap10000306

Kooij, D., \& Van de Voorde, K. (2011). How changes in subjective general health predict future time perspective, and development and generativity motives over the lifespan. Journal of Occupational and Organizational Psychology, 84, 228-247. doi:10.1111/j.20448325.2010.02012.x

Kooij, D. T. A. M., Zacher, H., Wang, M., \& Heckhausen, J. (2020). Industrial and Organizational Psychology: Perspectives on Science and Practice, 13, 345-365. doi:10.1017/iop.2020.1

Kopelman, R. E. (1979). Directionally different expectancy theory predictions of work motivation and job satisfaction. Motivation and Emotion, 3, 299-317. doi:10.1007/BF01904232

Korman, A. K. (1970). Toward an hypothesis of work behavior. Journal of Applied Psychology, 54, 31-41. doi:10.1037/h0028656

Körner, A., Lechner, C. M., Pavlova, M. K., \& Silbereisen, R. K. (2015). Goal engagement in coping with occupational uncertainty predicts favorable career-related outcomes. Journal of Vocational Behavior, 88, 174-184. doi:10.1016/j.jvb.2015.03.001

Körner, A., Reitzle, M., \& Silbereisen, R. K. (2012). Work-related demands and life satisfaction: The effects of engagement and disengagement among employed and long-term unemployed people. Journal of Vocational Behavior, 80, 187-196. doi:10.1016/j.jvb.2011.05.004

Kröger, H. (2017). The stratifying role of job level for sickness absence and the moderating role of gender and occupational gender composition. Social Science \& Medicine, 186, 1-9. doi:10.1016/j.socscimed.2017.05.045 
Krumm, S., Grube, A., \& Hertel, G. (2013). No time for compromises: Age as a moderator of the relation between needs-supply fit and job satisfaction. European Journal of Work and Organizational Psychology, 22, 547-562. doi:10.1080/1359432X.2012.676248

Kubicek, B., Korunka, C., Raymo, J. M., \& Hoonakker, P. (2011). Psychological well-being in retirement: The effects of personal and gendered contextual resources. Journal of Occupational Health Psychology, 16, 230-246. doi:10.1037/a0022334

Lachman, M. E. (1986). Locus of control in aging research: A case for multidimensional and domain-specific assessment. Journal of Psychology and Aging, 1, 34-40. doi:10.1037/0882-7974.1.1.34

Lachman, M. E. (1991). Perceived control over memory aging: Developmental and intervention perspectives. Journal of Social Issues, 47, 159-175. doi:10.1111/j.15404560.1991.tb01840.x

Lachman, M. E. (2006). Perceived control over aging-related declines: Adaptive beliefs and behaviors. Current Directions in Psychological Science, 15, 282-286. doi:10.1111/j.1467-8721.2006.00453.x

Lachman, M. E., \& Firth, K. M. (2004). The adaptive value of feeling in control during midlife. In O. G. Brim, C. D. Ryff, \& R. Kessler (Eds.), How healthy are we?: A national study of well-being at midlife (pp. 320-349). Chicago, IL, US: University of Chicago Press.

Lachman, M. E., Neupert, S. D., \& Agrigoroaei, S. (2011). The relevance of control beliefs for health and aging. In K. W. Schaie \& S. L. Willis (Eds.), Handbook of the psychology of aging (pp. 175-190). doi:10.1016/b978-0-12-380882-0.00011-5

LaCroix, A. Z., \& Haynes, S. G. (1986). Gender differences in the stressfulness of workplace 
roles: A focus on work and health. In R. Barnett, G. Baruch, \& L. Biener (Eds.), Gender and stress (pp. 96-121). New York, NY, US: Free Press.

Landsbergis, P. A., Schnall, P. L., Deitz, D., Friedman, R., \& Pickering, T. (1992). The patterning of psychological attributes and distress by "job strain” and social support in a sample of working men. Journal of Behavioral Medicine, 15, 379-405.

doi:10.1007/bf00844730

Langer, E. J. (1975). The illusion of control. Journal of Personality and Social Psychology, 32, 311-328. doi:10.1037/0022-3514.32.2.311

Langer, E. (1979). The illusion of incompetence. In L. Perlmutter \& R. Monty (Eds.), Choice and perceived control (pp. 301-313). Hillsdale, NJ: Erlbaum.

Lawler, E. E., \& Suttle, J. L. (1973). Expectancy theory and job behavior. Organizational Behavior and Human Performance, 9, 482-503. doi:10.1016/0030-5073(73)90066-4

Lens, W., Simons, J., \& Dewitte, S. (2001). Student motivation and self-regulation as a function of future time perspective and perceived instrumentality. In S. Volet \& S. Järvelä (Eds.), Motivation in learning contexts: Theoretical advances and methodological implications (pp. 233-248). Elmsford, NY, US: Pergamon Press.

Lent, R. W., \& Brown, S. D. (2006). Integrating person and situation perspectives on work satisfaction: A social-cognitive view. Journal of Vocational Behavior, 69, 236-247. doi:10.1016/j.jvb.2006.02.006

Lent, R. W., \& Brown, S. D. (2013). Social cognitive model of career self-management: Toward a unifying view of adaptive career behavior across the life span. Journal of Counseling Psychology, 60, 557-568. doi:10.1037/a0033446

Lent, R. W., Brown, S. D., \& Hackett, G. (1994). Toward a unifying social cognitive theory of 
career and academic interest, choice, and performance. Journal of Vocational Behavior, 45, 79-122. doi:10.1006/jvbe.1994.1027

Leventhal, G. S. (1976). The distribution of rewards and resources in groups and organizations. In L. Berkowitz \& W. Walster (Eds.), Advances in experimental social psychology (vol. 9, pp. 91-131). doi:10.1016/s0065-2601(08)60059-3

Leventhal, G. S. (1980). What should be done with equity theory? In K. J. Gergen, M. S. Greenberg, \& R. H. Willis (Eds.), Social exchange (pp. 27-55). New York, NY, US: Springer.

Liu, M., McGonagle, A. K., \& Fisher, G. G. (2018). Sense of control, job stressors, and wellbeing: Inter-relations and reciprocal effects among older US workers. Work, Aging and Retirement, 4, 96-107. doi:10.1093/workar/waw035

Martinent, G., Bailly, N., Ferrand, C., Gana, K., Giraudeau, C., \& Joulain, M. (2017). Longitudinal patterns of stability and change in tenacious goal pursuit and flexible goal adjustment among older people over a 9-year period. BioMed Research International, 8017541. doi:10.1155/2017/8017541

Maurer, T. J. (2001). Career-relevant learning and development, worker age, and beliefs about self-efficacy for development. Journal of Management, 27, 123-140. doi:10.1177/014920630102700201

McCarthy, A., Darcy, C., \& Grady, G. (2010). Work-life balance policy and practice: Understanding line manager attitudes and behaviors. Human Resource Management Review, 20, 158-167. doi:10.1016/j.hrmr.2009.12.001

McGonagle, A. K., \& Barnes-Farrell, J. L. (2014). Chronic illness in the workplace: Stigma, identity threat and strain. Stress and Health, 30, 310-321. doi:10.1002/smi.2518 
McKnight, J. D., \& Glass, D. C. (1995). Perceptions of control, burnout, and depressive symptomatology: A replication and extension. Journal of Consulting and Clinical Psychology, 63, 490-494. doi:10.1037/0022-006X.63.3.490

Meier, L. L., Semmer, N. K., Elfering, A., \& Jacobshagen, N. (2008). The double meaning of control: Three-way interactions between internal resources, job control, and stressors at work. Journal of Occupational Health Psychology, 13, 244-258. doi:10.1037/10768998.13.3.244

Mirowsky, J. (1995). Age and the sense of control. Social Psychology Quarterly, 58, 31-43. doi: $10.2307 / 2787141$

Mitchell, T. R., \& Knudsen, B. W. (1973). Instrumentality theory predictions of students' attitudes towards business and their choice of business as an occupation. The Academy of Management Journal, 16, 41-52. doi:10.2307/255041

Mitchell, T. R., \& Biglan, A. (1971). Instrumentality theories: Current uses in psychology. Psychological Bulletin, 76, 432-454. doi:10.1037/h0031831

Moghimi, D., Zacher, H., Scheibe, S., \& Van Yperen, N. W. (2017). The selection, optimization, and compensation model in the work context: A systematic review and meta-analysis of two decades of research. Journal of Organizational Behavior, 38, 247-275. doi:10.1002/job.2108

Müller, A., De Lange, A., Weigl, M., Van der Heijden, B., Ackermans, J., \& Wilkenloh, J. (2015). Task performance among employees above age 65: The role of cognitive functioning and job demand-control. Work, Aging and Retirement, 1, 296-308. doi:10.1093/workar/wav001 
Müller, A., Weigl, M., Heiden, B., Rudolph, C. W., \& Angerer, P. (2017). The age-related effect of job autonomy on depressive symptoms through selective optimization with compensation: A two-wave panel study. Work, Aging and Retirement, 3, 379-392. doi:10.1093/workar/wax004

Ng, T. W. H., \& Feldman, D. C. (2015). The moderating effects of age in the relationships of job autonomy to work outcomes. Work, Aging and Retirement, 1, 64-78. doi:10.1093/workar/wau003

Ng, T. W. H., Sorenson, K. L., \& Eby, L. T. (2006). Locus of control at work: A meta-analysis. Journal of Organizational Behavior, 27, 1057-1087. doi:10.1002/job.416

Niessen, C., Heinrichs, N., \& Dorr, S. (2011). Pursuit and adjustment of goals during unemployment: The role of age. International Journal of Stress Management, 16, 102123. doi: $10.1037 / \mathrm{a} 0015683$

Niessen, C., Swarowsky, C., \& Leiz, M. (2010). Age and adaptation to changes in the workplace. Journal of Managerial Psychology, 25, 356-383. doi:10.1108/02683941011035287

O’Brien, G. E. (1984). Locus of control, work, and retirement. In M. Lefcourt (Ed.), Research with the locus of control construct: Extensions and limitations (pp. 7-72). doi:10.1016/b978-0-12-443203-1.50006-5

Oerlemans, W. G. M., \& Bakker, A. B. (2018). Motivating job characteristics and happiness at work: A multilevel perspective. Journal of Applied Psychology, 103, 1230-1241. doi:10.1037/ap10000318

Olson, J. M., Roese, N. J., \& Zanna, M. P. (1996). Expectancies. In E. T. Higgins \& A. W. Kruglanski (Eds.), Social psychology; Handbook of basic principles (pp. 211-238). New York, NY, US: Guilford Press. 
Opp, K.-D. (2001). How do norms emerge? An outline of a theory. Mind \& Society, 3, 101-128. doi:10.1007/bf02512077

Packer, E. (1985). Understanding the subconscious. The Objectivist Forum, 6, 1-10.

Pansu, P. (1997). The norm of internality in an organizational context. European Journal of Work and Organizational Psychology, 6, 37-58. doi:10.1080/135943297399286

Parker, R. J., Nouri, H., \& Hayes, A. F. (2011). Distributive justice, promotion instrumentality, and turnover intentions in public accounting firms. Behavioral Research in Accounting, 23, 169-186. doi:10.2308/bria-50020

Paulhus, D. (1983). Sphere-specific measures of perceived control. Journal of Personality and Social Psychology, 44, 1253-1265. doi:10.1037/0022-3514.44.6.1253

Paulhus, D., \& Christie, R. (1981). Spheres of control: An interactionist approach to assessment of perceived control. In H. M. Lefcourt (Ed.), Research with the locus of control construct (pp. 161-188). doi:10.1016/B978-0-12-443201-7.50009-9

Pavlova, M. K., \& Silbereisen, R. K. (2013). Dispositional optimism fosters opportunitycongruent coping with occupational uncertainty. Journal of Personality, 81, 76-86. doi:10.1111/j.1467-6494.2012.00782.x

Perrewé, P. L., \& Anthony, W. P. (1990). Stress in a steel pipe mill: The impact of job demands, personal control, and employee age on somatic complaints. Journal of Social Behavior and Personality, 5, 77-90. doi:10.1002/job.4030100303

Peterson, C., \& Stunkard, A. J. (1992). Cognates of personal control: Locus of control, selfefficacy, and explanatory style. Applied \& Preventive Psychology, 1, 111-117. doi:10.1016/s0962-1849(05)80151-9

Petrou, P., Demerouti, E., Peeters, M. C. W., Schaufeli, W. B., \& Hetland, J. (2012). Crafting a 
job on a daily basis : Contextual correlates and the link to work engagement. Journal of Organizational Behavior, 33, 1120-1141. doi:10.1002/job.1783

Pinder, C. G. (2008). Expectancy-valence theories of work motivation. In C. G. Pinder (Ed.), Work motivation in organizational behavior (2nd ed, pp. 363-388). Upper Saddle River, NJ: Prentice-Hall.

Rauvola, R. S., \& Rudolph, C. W. (2020). On the limits of agency for successful aging at work. Industrial and Organizational Psychology: Perspectives on Science and Practice, 13, 383-387. doi:10.1017/iop.2020.61

Rauvola, R. S., Rudolph, C. W., \& Zacher, H. (2021, in press). Handling time in contemporary occupational stress \& well-being research: Considerations, examples, and recommendations. Research in Occupational Stress and Well Being.

Raver, J. L., Erhart, M. G., \& Chadwick, I. C. (2012). The emergence of team helping norms: Foundations within members' attributes and behavior. Journal of Organizational Behavior, 33, 616-637. doi:10.1002/job.772

Raynor, J. O. (1969). Future orientation and motivation of immediate activity: An elaboration of the theory of achievement motivation. Psychological Review, 76, 606-610. doi:10.1037/h0028291

Rodin, J. (1986). Health, control, and aging. In M. M. Baltes \& P. B. Baltes (Eds.), The psychology of control and aging (pp. 139-165). Hillsdale, NJ, US: Lawrence Erlbaum.

Rodin, J. (1990). Control by any other name: Definitions, concepts, and processes. In J. Rodin, C. Schooler, \& K. W. Schaie (Eds.), Self-directedness: Cause and effects throughout the life course (pp. 1-17). Hillsdale, NJ: Lawrence Erlbaum.

Rodríguez, I., Bravo, M. J., Peiró, J. M., \& Schaufeli, W. (2001). The demands-control-support 
model, locus of control and job dissatisfaction: A longitudinal study. Work \& Stress, 15, 97-114. doi:10.1080/02678370110066968

Roth, S. (1980). A revised model of learned helplessness in humans. Journal of Personality, 48, 103-133. doi:10.1111/j.1467-6494.1980.tb00969.x

Rothbaum, F., Weisz, J. R., \& Snyder, S. S. (1982). Changing the world and changing the self: A two-process model of perceived control. Attitudes and Social Cognition, 42, 5-37. doi:10.1037/0022-3514.42.1.5

Rotter, J. B. (1955). The role of the psychological situation in determining the direction of human behavior. In M. R. Jones (Ed.), Nebraska symposium on motivation: 1955 (pp. 245-269). Lincoln, NE,: University of Nebraska Press.

Rotter, J. B. (1966). Generalized expectancies for internal versus external control of reinforcement. Psychological Monographs: General and Applied, 80, 1-28. doi:10.1037/h0092976

Rotter, J. B., Fitzgerald, B. J., \& Joyce, J. N. (1954). A comparison of some objective measures of expectancy. The Journal of Abnormal and Social Psychology, 49, 111-114. doi:10.1037/h0059837

Rottinghaus, P. J., Larson, L. M., \& Borgen, F. H. (2003). The relation of self-efficacy and interests: A meta-analysis of 60 samples. Journal of Vocational Behavior, 62, 221-236. doi:10.1016/S0001-8791(02)00039-8

Rudolph, C. W. (2016). Lifespan developmental perspectives on working: A literature review of motivational theories. Work, Aging and Retirement, 2, 130-158. doi:10.1093/workar/waw012

Rudolph, C. W., Kooij, D. T. A. M., Rauvola, R. S., \& Zacher, H. (2018). Occupational future 
time perspective: A meta-analysis of antecedents and outcomes. Journal of Organizational Behavior, 39, 229-248. doi:10.1002/job.2264

Ryff, C. D. (1995). Psychological well-being in adult life. Current Directions in Psychological Science, 4, 99-104. doi:10.1111/1467-8721.ep10772395

Sadler-Smith, E., El-Kot, G., \& Leat, M. (2003). Differentiating work autonomy facets in a nonWestern context. Journal of Organizational Behavior, 24, 709-731. doi:10.1002/job.200

Sadri, G., \& Robertson, I. T. (1993). Self-efficacy and work-related behaviour: A review and meta-analysis. Applied Psychology, 42, 139-152. doi:10.1111/j.14640597.1993.tb00728.x

Salanova, M., Peiró, J. M., \& Schaufeli, W. B. (2002). Self-efficacy specificity and burnout among information technology workers: An extension of the job demand-control model. European Journal of Work and Organizational Psychology, 11, 1-25. doi:10.1080/13594320143000735

Salmela-Aro, K. (2009). Personal goals and well-being during critical life transitions: The four C's - Channelling, choice, co-agency and compensation. Advances in Life Course Research, 14, 63-73. doi:10.1016/j.alcr.2009.03.003

Scheibe, S., \& Zacher, H. (2013). A lifespan perspective on emotion regulation, stress, and wellbeing in the workplace. In P. L. Perrewé, C. C. Rosen, \& J. R. B. Halbesleben (Eds.), Research in occupational stress and well-being: The role of emotion and emotion regulation in job stress and well being (pp. 163-193). doi:10.1108/s14793555(2013)0000011010

Schriesheim, C. A., Castro, S. L., Zhou, X., \& DeChurch, L. A. (2006). An investigation of path- 
goal and transformational leadership theory predictions at the individual level of analysis. The Leadership Quarterly, 17, 21-38. doi:10.1016/j.leaqua.2005.10.008

Schulz, R., \& Heckhausen, J. (1999). Aging, culture and control: Setting a new research agenda. The Journals of Gerontology Series B: Psychological Sciences and Social Sciences, 54, 139-145. doi:10.1093/geronb/54b.3.p139

Shultz, K. S., Wang, M., Crimmins, E. M., \& Fisher, G. G. (2010). Age differences in the demand-control model of work stress: An examination of data from 15 European countries. Journal of Applied Gerontology, 29, 21-47. doi:10.1177/0733464809334286

Scott, W. E. (1966). Activation theory and task design. Organizational Behavior and Human Performance, 1, 3-30. doi:10.1016/0030-5073(66)90003-1

Seligman, M. E. P. (1975). Helplessness: On depression, development, and death. San Francisco, CA, US: Freeman.

Shane, J., \& Heckhausen, J. (2012). Motivational self-regulation in the work domain: Congruence of individuals' control striving and the control potential in their developmental ecologies. Research in Human Development, 9, 337-357. doi:10.1080/15427609.2012.729918

Shane, J., \& Heckhausen, J. (2016). Optimized engagement across life domains in adult development: Balancing diversity and interdomain consequences. Research in Human Development, 13, 280-296. doi:10.1080/15427609.2016.1234308

Shane, J., Hamm, J., \& Heckhausen, J. (2019). Subjective age at work: Feeling younger or older than one's actual age predicts perceived control and motivation at work. Work, Aging and Retirement, 5, 323-332. doi:10.1093/workar/waz013

Shoji, K., Cieslak, R., Smoktunowicz, E., Rogala, A., Benight, C., \& Luszczynska, A. (2016). 
Associations between job burnout and self-efficacy: A meta-analysis. Anxiety, Stress, and Coping, 29, 367-386. doi:10.1080/10615806.2015.1058369

Sheldon, K. M., \& Elliot, A. J. (1999). Goal striving, need satisfaction, and longitudinal wellbeing: The self-concordance model. Journal of Personality and Social Psychology, 76, 482-497. doi:10.1037/0022-3514.76.3.482

Simons, J., Dewitte, S., \& Lens, W. (2000). Wanting to have vs. wanting to be: The effect of perceived instrumentality on goal orientation. British Journal of Psychology, 91, 335351. doi:10.1348/000712600161862

Sitkin, S. B., Long, C. P., \& Cardinal, L. B. (2020). Assessing the control literature: Looking back and looking forward. Annual Review of Organizational Psychology and Organizational Behavior, 7, 339-368. doi:10.1146/annurev-orgpsych-012119-045321

Siu, O. L., Spector, P. E., Cooper, C. L., \& Donald, I. (2001). Age differences in coping and locus of control: A study of managerial stress in Hong Kong. Psychology and Aging, 16, 707-710. doi:10.1037/0882-7974.16.4.707

Skinner, E. A. (1996). A guide to constructs of control. Journal of Personality and Social Psychology, 71, 549-570. doi:10.1037/0022-3514.71.3.549

Skinner, E. A. (1999). Action regulation, coping, and development. In J. Brandtstädter \& R. M. Lerner (Eds.), Action \& self-development: Theory and research through the lifespan (pp. 465-504). doi:10.4135/9781452204802.n16

Smith, R. E. (1989). Effects of coping skills training on generalized self-efficacy and locus of control. Personality Processes and Individual Differences, 56, 228-233. doi:10.1037/0022-3514.56.2.228

Smith, C. S., Tisak, J., Hahn, S. E., \& Schmieder, R. A. (1997). The measurement of job control. 
Journal of Organizational Behavior, 18, 225-237. doi:10.1002/(sici)1099-

1379(199705)18:3<225::aid-job797>3.0.co;2-e

Spector, P. E. (1982). Behavior in organizations as a function of employee's locus of control.

Psychological Bulletin, 91, 482-497. doi:10.1037/0033-2909.91.3.482

Spector, P. E. (1986). Perceived control by employees: A meta-analysis of studies concerning autonomy and participation at work. Human Relations, 39, 1005-1016.

doi:10.1177/001872678603901104

Spector, P. E. (1988). Development of the work locus of control scale. Journal of Occupational Psychology, 61, 335-340. doi:10.1111/j.2044-8325.1988.tb00470.x

Spector, P. E. (2002). Employee control and occupational stress. Current Directions in Psychological Science, 11, 133-136. doi:10.1111/1467-8721.00185

Spector, P. E., \& Jex, S. M. (1991). Relations of job characteristics from multiple data sources with employee affect, absence, turnover intentions, and health. Journal of Applied Psychology, 76, 46-53. doi:10.1037/0021-9010.76.1.46

Spiegel, S., Grant-Pillow, H., \& Higgins, E. T. (2004). How regulatory fit enhances motivational strength during goal pursuit. European Journal of Social Psychology, 34, 39-54. doi:10.1002/ejsp.180

Stajkovic, A. D., \& Luthans, F. (1998a). Self-efficacy and work-related performance: A metaanalysis. Psychological Bulletin, 124, 240-261. doi:10.1037/0033-2909.124.2.240

Stajkovic, A. D., \& Luthans, F. (1998b). Social cognitive theory and self-efficacy: Going beyond traditional motivational and behavioral approaches. Organizational Dynamics, 26, 62-74. doi:10.1016/S0090-2616(98)90006-7

Sterns, H. L., Barrett, G. V., Czaja, S. J., \& Barr, J. K. (1994). Issues in work and aging. 
Journal of Applied Gerontology, 13, 7-19. doi:10.1177/073346489401300102

Sterns, H. L., \& Dorsett, J. G. (1994). Career development: A life-span issue. Experimental Aging Research, 20, 257-264. doi:10.1080/03610739408253975

Strauser, D. R., Ketz, K., \& Keim, J. (2002). The relationship between self-efficacy, locus of control and work personality. Journal of Rehabilitation, 68, 20-26. doi:10.1037/t36041000

Strecher, V. J., DeVellis, B. M., Becker, M. H., \& Rosenstock, I. M. (1986). The role of selfefficacy in achieving health behavior change. Health Education Quarterly, 13, 73-91. doi:10.1177/109019818601300108

Sutton, R., \& Kahn, R. L. (1986). Prediction, understanding, and control as antidotes to organizational stress. In J. Lorsch (Ed.), Handbook of Organizational Behavior (pp. 272285). Englewood Cliffs, NJ: Prentice-Hall.

Taris, T. W. (2006). Bricks without clay: On urban myths in occupational health psychology. Work \& Stress, 20, 99-104. doi:10.1080/02678370600893410

Taris, T. W., Stoffelsen, J., Bakker, A. B., Schaufeli, W. B., \& van Dierendonck, D. (2005). Job control and burnout across occupations. Psychological Reports, 97, 955-961. doi:10.2466/pr0.97.3.955-961

Tetrick, L. E., \& LaRocco, J. M. (1987). Understanding, prediction, and control as moderators of the relationships between perceived stress, satisfaction, and psychological well-being. Journal of Applied Psychology, 72, 538-543. doi:10.1037/0021-9010.72.4.538

Theurer, C. P., Tumasjan, A., \& Welpe, I. M. (2018). Contextual work design and employee innovative work behavior: When does autonomy matter? PLoS ONE, 13, 1-35. doi:10.1371/journal.pone.0204089 
Thibaut, J., \& Walker, L. (1975). Procedural justice: A psychological analysis. Hillsdale, NJ, US: Erlbaum.

Thompson, S. C., \& Spacapan, S. (1991). Perceptions of control in vulnerable populations. Journal of Social Issues, 47, 1-21. doi:10.1111/j.1540-4560.1991.tb01831.x

Tims, M., Bakker, A. B., \& Derks, D. (2013). The impact of job crafting on job demands, job resources, and well-being. Journal of Occupational Health Psychology, 18, 230-240. doi:10.1037/a0032141

Tolman, E. (1934). Theories of learning. In F. A. Moss (Ed.), Comparative psychology. New York, NY: Prentice-Hall.

Tomasik, M. J., Knecht, M., \& Freund, A. M. (2017). Some evidence for the usefulness of an optimal foraging theory perspective on goal conflict and goal facilitation. Journal of Personality and Social Psychology, 113, 962-980. doi:10.1037/pspp0000165

Turner, A. N., \& Lawrence, P. R. (1965). Industrial jobs and the worker. Boston, MA: Harvard Graduate School of Business Administration.

Truxillo, D. M., Cadiz, D. M., Rineer, J. R., Zaniboni, S., \& Fraccaroli, F. (2012). A lifespan perspective on job design: Fitting the job and the worker to promote job satisfaction, engagement, and performance. Organizational Psychology Review, 2, 340-360. doi:10.1177/2041386612454043

Urry, H. L., \& Gross, J. J. (2010). Emotion regulation in older age. Current Directions in Psychological Science, 19, 352-357. doi:10.1177/0963721410388395

Vancouver, J. B., More, K. M., \& Yoder, R. J. (2008). Self-efficacy and resource allocation: Support for a nonmonotonic, discontinuous model. Journal of Applied Psychology, 93, 35-47. doi:10.1037/0021-9010.93.1.35 
van den Berg, P. T., \& Feij, J. A. (2003). Complex relationships among personality traits, job characteristics, and work behaviors. International Journal of Selection and Assessment, 11, 326-339. doi:10.1111/j.0965-075x.2003.00255.x

Van der Horst, A. C., Klehe, U. C., \& Van der Heijden, B. I. (2017). Adapting to a looming career transition: How age and core individual differences interact. Journal of Vocational Behavior, 99, 132-145. doi:10.1016/j.jvb.2018.08.004

Van Eerde, W., \& Thierry, H. (1996). Vroom's expectancy models and work-related criteria: A meta-analysis. Journal of Applied Psychology, 81, 575-586. doi:10.1037/00219010.81 .5 .575

van Rooij, S. W. (2012). Training older workers: Lessons learned, unlearned, and relearned from the field of instructional design. Human Resource Management, 51, 281-298. doi:10.1002/hrm.21466

Vroom, V. H. (1964). Work and motivation. New York, NY, US: Wiley.

Wang, Q., Bowling, N. A., \& Eschleman, K. J. (2010). A meta-analytic examination of work and general locus of control. Journal of Applied Psychology, 95, 761-768. doi:10.1037/a0017707

Weigl, M., Müller, A., Hornung, S., Zacher, H., \& Angerer, P. (2013). The moderating effects of job control and selection, optimization, and compensation strategies on the age-work ability relationship. Journal of Organizational Behavior, 34, 607-628. doi:10.1002/job.1810

Weiner, B. (1985). An attributional theory of achievement motivation and emotion. Psychological Review, 92, 548-573. doi:10.1037/0033-295x.92.4.548

Weiner, B., Frieze, I., Kukla, A., Reed, L., Rest, S., \& Rosenbaum, R. M. (1971). Perceiving the 
causes of success and failure. Morristown, NJ: General Learning Press.

Weiner, B., Heckhausen, H., Meyer, W.-U., \& Cook, R. E. (1972). Causal ascriptions and achievement behavior: A conceptual analysis of effort and reanalysis of locus of control. Journal of Personality and Social Psychology, 21, 239-248. doi:10.1037/h0032307

Weisz, J. R., Rothbaum, F. M., \& Blackburn, T. C. (1984). Standing out and standing in: The psychology of control in America and Japan. American Psychologist, 39, 955-969. doi:10.1037/0003-066x.39.9.955

White, A. T., \& Spector, P. E. (1987). An investigation of age-related factors in the age-jobsatisfaction relationship. Psychology and Aging, 2, 261-265. doi:10.1037/08827974.2.3.261

Wolinsky, F. D., Vander Weg, M. W., Martin, R., Unverzagt, F. W., Willis, S. L., Marsiske, M., ...Tennstedt, S. L. (2010). Does cognitive training improve internal locus of control among older adults? The Journals of Gerontology Series B: Psychological Sciences and Social Sciences, 65, 591-598. doi:10.1093/geronb/gbp117

Wu, C. H., Griffin, M. A., \& Parker, S. K. (2015). Developing agency through good work: Longitudinal effects of job autonomy and skill utilization on locus of control. Journal of Vocational Behavior, 89, 102-108. doi:10.1016/j.jvb.2015.05.004

Xanthopoulou, D., Bakker, A. B., Demerouti, E., \& Schaufeli, W. B. (2007). The role of personal resources in the job demands-resources model. International Journal of Stress Management, 14, 121-141. doi:10.1037/1072-5245.14.2.121

Xanthopoulou, D., Bakker, A. B., Heuven, E., Demerouti, E., \& Schaufeli, W. B. (2008). Working in the sky : A diary study on work engagement among flight attendants. Journal of Occupational Health Psychology, 13, 345-356. doi:10.1037/1076-8998.13.4.345 
Yamaguchi, S. (2001). Culture and control orientations. In D. Matsumoto (Ed.), The handbook of culture and psychology (pp. 223-243). New York, NY, US: Oxford University Press.

Zacher, H., Feldman, D. C., \& Schulz, H. (2014). Age, occupational strain, and well-being: A person-environment fit perspective. Research in Occupational Stress and Well Being, 12, 83-111. doi:10.1108/S1479-355520140000012002

Zacher, H., Hacker, W., \& Frese, M. (2016). Action regulation across the adult lifespan (ARAL): A metatheory of work and aging. Work, Aging and Retirement, 2, 286-306. doi:10.1093/workar/waw015

Zacher, H., \& Schmitt, A. (2016). Work characteristics and occupational well-being: The role of age. Frontiers in Psychology, 7, 1-8. doi:10.3389/fpsyg.2016.01411 
Table 1

Lifespan Control Framework Construct Definitions and Relevant Attributes

\begin{tabular}{|c|c|c|c|c|}
\hline Variable & Key Question & Definition & $\begin{array}{l}\text { Theories and/or Key } \\
\text { Citation(s) }\end{array}$ & $\begin{array}{c}\text { Applications to Age and Aging at } \\
\text { Work }\end{array}$ \\
\hline (1) Control & $\begin{array}{l}\text { Do I have a choice about } \\
\text { how I act and what } \\
\text { outcome results? }\end{array}$ & $\begin{array}{l}\text { An individual's situational } \\
\text { discretion, power, or influence } \\
\text { over their actions, } \\
\text { accompanied by the ability to } \\
\text { successfully engage in chosen } \\
\text { actions and/or to receive } \\
\text { rewards or desired outcomes } \\
\text { as a result of their choice and } \\
\text { actions }\end{array}$ & $\begin{array}{l}\text { Chanowitz \& Langer } \\
\text { (1980); Ganster \& Fusilier } \\
\text { (1989); Rodin (1990); } \\
\text { Skinner (1996); Thompson } \\
\text { \& Spacapan (1991) }\end{array}$ & \\
\hline \multirow[t]{2}{*}{$\begin{array}{l}\text { (1.1) "Actual" } \\
\text { Control }\end{array}$} & \multirow[t]{2}{*}{$\begin{array}{l}\text { Are necessary contextual } \\
\text { and personal attributes } \\
\text { present to provide me with } \\
\text { action choice and/or } \\
\text { outcome obtainment? }\end{array}$} & \multirow[t]{2}{*}{$\begin{array}{l}\text { An objective level of available } \\
\text { choices and a) the ability to } \\
\text { perform or b) obtain a } \\
\text { particular desired outcome as a } \\
\text { result of these choices and } \\
\text { performance in a given } \\
\text { scenario }\end{array}$} & \multirow[t]{2}{*}{$\begin{array}{l}\text { Lachman et al. (2011); } \\
\text { Langer (1979); Skinner } \\
(1996)\end{array}$} & $\begin{array}{l}\text { Biopsychosocial changes with age: } \\
\text { What objective resources and } \\
\text { constraints result from physical and } \\
\text { interpersonal aging processes (e.g., } \\
\text { ageism, discrimination, changes in } \\
\text { capacities and abilities) and how do } \\
\text { these impact aging workers? }\end{array}$ \\
\hline & & & & $\begin{array}{l}\text { How do age-related changes } \\
\text { intersect with other identities, life } \\
\text { contexts, and perceptual processes? }\end{array}$ \\
\hline \multirow[t]{2}{*}{$\begin{array}{l}\text { (1.2) Perceived } \\
\text { Control }\end{array}$} & \multirow[t]{2}{*}{$\begin{array}{l}\text { In my opinion, do I have } \\
\text { action choice and/or } \\
\text { outcome control? }\end{array}$} & \multirow[t]{2}{*}{$\begin{array}{l}\text { An individual's belief(s) about } \\
\text { the availability of control, } \\
\text { generally or in particular } \\
\text { contexts }\end{array}$} & \multirow[t]{2}{*}{$\begin{array}{l}\text { Flammer (1997); Skinner } \\
\text { (1996) }\end{array}$} & $\begin{array}{l}\text { Experience of age and related } \\
\text { changes: } \\
\text { How does an individual's outlook } \\
\text { on age-related gains and losses } \\
\text { shape their beliefs about } \\
\text { competence and contingencies, in } \\
\text { and out of work? }\end{array}$ \\
\hline & & & & $\begin{array}{l}\text { To what extent can workers' beliefs } \\
\text { contradict or overcome actual } \\
\text { limitations across the lifespan? }\end{array}$ \\
\hline
\end{tabular}




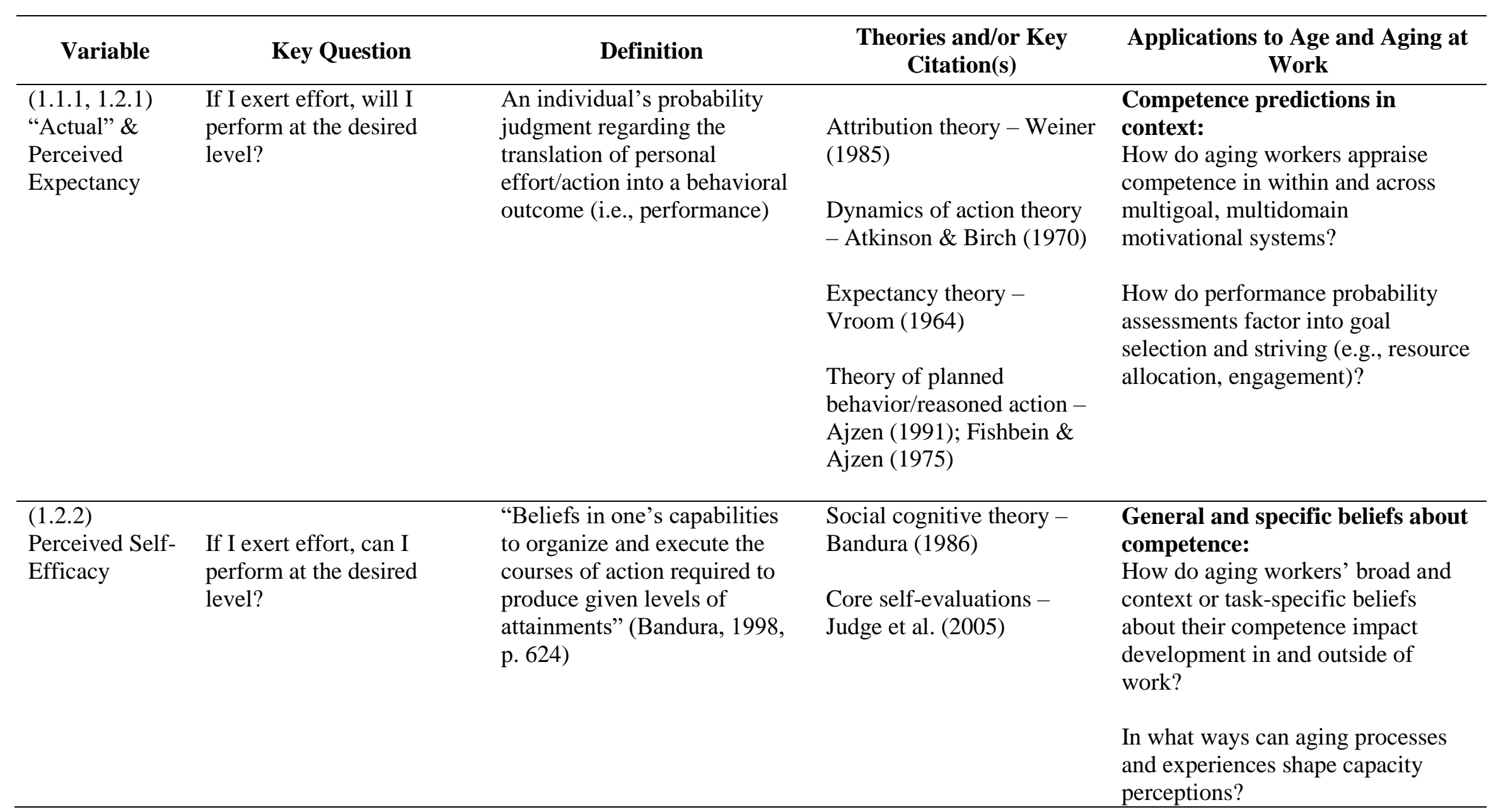




\begin{tabular}{|c|c|c|c|c|}
\hline Variable & Key Question & Definition & $\begin{array}{c}\text { Theories and/or Key } \\
\text { Citation(s) }\end{array}$ & $\begin{array}{c}\text { Applications to Age and Aging at } \\
\text { Work }\end{array}$ \\
\hline $\begin{array}{l}\text { (1.1.2, 1.2.3) } \\
\text { "Actual" \& } \\
\text { Perceived } \\
\text { Types of } \\
\text { Autonomy/ } \\
\text { Control }\end{array}$ & $\begin{array}{l}\text { Do I have the discretion } \\
\text { and choice required to } \\
\text { perform at this level? }\end{array}$ & $\begin{array}{l}\text { Job autonomy/control: "The } \\
\text { extent to which individual } \\
\text { employees can structure and } \\
\text { control how and when they do } \\
\text { their particular job tasks" } \\
\text { (Spector, 1986, p. 1006) }\end{array}$ & $\begin{array}{l}\text { Job characteristics model - } \\
\text { Hackman \& Oldham (1976) } \\
\text { Job demands-control(- } \\
\text { support) model - Karasek } \\
\text { (1979), Karasek \& Theorell } \\
\text { (1990) } \\
\text { Job demands-resources } \\
\text { model - Demerouti et al. } \\
\text { (2001) } \\
\text { Conservation of resources } \\
\text { theory - Hobfoll (1989) }\end{array}$ & $\begin{array}{l}\text { Job design and functioning: } \\
\text { What job configurations (i.e., } \\
\text { demands, resources) best fit with } \\
\text { and support the performance and } \\
\text { well-being of employees as they } \\
\text { age? } \\
\text { How does job design interact with } \\
\text { other forms of control, in addition to } \\
\text { individual differences and context, } \\
\text { to shape work outcomes for older } \\
\text { adults? }\end{array}$ \\
\hline $\begin{array}{l}(1.1 .3,1.2 .4) \\
\text { "Actual" \& } \\
\text { Perceived } \\
\text { Instrumentality }\end{array}$ & $\begin{array}{l}\text { If I perform at this level, } \\
\text { will I receive desired } \\
\text { outcomes as a result of my } \\
\text { performance? }\end{array}$ & $\begin{array}{l}\text { An individual's probability } \\
\text { judgment regarding the } \\
\text { translation of performance into } \\
\text { desired outcome(s) }\end{array}$ & $\begin{array}{l}\text { Modified instrumentality } \\
\text { theory - Graen (1969) } \\
\text { Path-goal leadership theory } \\
\text { - House \& Mitchell (1975) } \\
\text { Equity theory/justice - } \\
\text { Adams (1965) } \\
\text { Social norm emergence - } \\
\text { Opp (2001) }\end{array}$ & $\begin{array}{l}\text { Contingency predictions in } \\
\text { context: } \\
\text { How do aging workers appraise } \\
\text { contingencies in complex } \\
\text { organizational environments (i.e., } \\
\text { multilevel norms, leadership, other } \\
\text { influences)? } \\
\text { How do reward probability } \\
\text { assessments factor into goal } \\
\text { selection and striving (e.g., progress } \\
\text { monitoring, timing, revision)? }\end{array}$ \\
\hline
\end{tabular}




\begin{tabular}{|c|c|c|c|c|}
\hline Variable & Key Question & Definition & $\begin{array}{c}\text { Theories and/or Key } \\
\text { Citation(s) }\end{array}$ & $\begin{array}{c}\text { Applications to Age and Aging at } \\
\text { Work }\end{array}$ \\
\hline $\begin{array}{l}(1.2 .5) \\
\text { Perceived } \\
\text { Locus of } \\
\text { Control }\end{array}$ & $\begin{array}{l}\text { Are the outcomes I receive } \\
\text { a result of my performance } \\
\text { or a result of uncontrollable } \\
\text { forces? }\end{array}$ & $\begin{array}{l}\text { "A belief that a response will, } \\
\text { or will not, influence the } \\
\text { attainment of reinforcement" } \\
\text { (Furnham \& Steele, 1993, p. } \\
444)\end{array}$ & $\begin{array}{l}\text { Core self-evaluations - } \\
\text { Judge et al. (2005) } \\
\text { Social learning theory - } \\
\text { Rotter (1966) } \\
\text { Implicit personality theory } \\
\text { - Dweck \& Leggett (1988) }\end{array}$ & $\begin{array}{l}\text { General and specific beliefs about } \\
\text { contingencies: } \\
\text { How do aging workers' broad and } \\
\text { context-specific beliefs about results } \\
\text { and reward contingencies impact } \\
\text { work and life decision-making? } \\
\text { How do aging processes and } \\
\text { experiences shape contingency } \\
\text { perceptions? }\end{array}$ \\
\hline $\begin{array}{l}\text { (1.3) Enacted } \\
\text { Control }\end{array}$ & $\begin{array}{l}\text { How can I maximize gains } \\
\text { and minimize losses over } \\
\text { time and across contexts? }\end{array}$ & $\begin{array}{l}\text { Individuals' engagement in } \\
\text { specific control-based } \\
\text { strategies to self-regulate } \\
\text { development and functioning } \\
\text { across the lifespan }\end{array}$ & Heckhausen et al. (2010) & $\begin{array}{l}\text { Management of age and age- } \\
\text { related changes: } \\
\text { How do individuals "age } \\
\text { successfully" in and outside of } \\
\text { work? } \\
\text { To what extent can workers self- } \\
\text { regulate to overcome actual or } \\
\text { perceived limitations across the } \\
\text { lifespan? }\end{array}$ \\
\hline $\begin{array}{l}\text { (1.3.1) Primary } \\
\text { Control }\end{array}$ & $\begin{array}{l}\text { How can I change the } \\
\text { situation to fit my } \\
\text { needs/abilities and } \\
\text { resources? }\end{array}$ & $\begin{array}{l}\text { Individuals' attempts, using a } \\
\text { variety of strategies and } \\
\text { resources, to change their } \\
\text { environment to be in line with } \\
\text { their needs and goals }\end{array}$ & $\begin{array}{l}\text { Motivational theory of } \\
\text { control / of lifespan } \\
\text { development - Heckhausen } \\
\text { et al. (2010), Heckhausen \& } \\
\text { Schulz (1995) }\end{array}$ & $\begin{array}{l}\text { Alignment of the environment } \\
\text { with the aging worker: } \\
\text { In what ways can aging workers } \\
\text { most effectively act upon the (work) } \\
\text { environment to fit their priorities } \\
\text { and functioning? }\end{array}$ \\
\hline & & & $\begin{array}{l}\text { Assimilative and } \\
\text { accommodative coping - } \\
\text { Brandtstädter \& Renner } \\
(1990)\end{array}$ & $\begin{array}{l}\text { How can workplaces train or } \\
\text { support the aging workforce to } \\
\text { engage in mutually adaptive } \\
\text { primary control striving? }\end{array}$ \\
\hline
\end{tabular}




\begin{tabular}{|c|c|c|c|c|}
\hline Variable & Key Question & Definition & $\begin{array}{l}\text { Theories and/or Key } \\
\text { Citation(s) }\end{array}$ & $\begin{array}{c}\text { Applications to Age and Aging at } \\
\text { Work }\end{array}$ \\
\hline $\begin{array}{l}(1.3 .2) \\
\text { Secondary } \\
\text { Control }\end{array}$ & $\begin{array}{l}\text { How can I change myself to } \\
\text { fit the constraints of the } \\
\text { situation? }\end{array}$ & $\begin{array}{l}\text { Individuals' attempts to } \\
\text { change themselves, such as } \\
\text { their goals or needs, to be in } \\
\text { line with the constraints or } \\
\text { limitations of their } \\
\text { environment and support } \\
\text { primary control }\end{array}$ & $\begin{array}{l}\text { Selective optimization with } \\
\text { compensation - Baltes \& } \\
\text { Baltes (1990) } \\
\text { Socioemotional selectivity } \\
\text { theory - Carstensen et al. } \\
\text { (1999) } \\
\text { Action regulation across the } \\
\text { adult lifespan - Zacher, } \\
\text { Hacker, \& Frese (2016) } \\
\text { Goal self-concordance - } \\
\text { Sheldon \& Elliot (1999) }\end{array}$ & $\begin{array}{l}\text { Alignment of the aging worker } \\
\text { with the environment: } \\
\text { In what ways can aging workers } \\
\text { most effectively adapt themselves } \\
\text { (at work) to fit their limitations? } \\
\text { How can workplaces train or } \\
\text { support the aging workforce to } \\
\text { engage in mutually adaptive } \\
\text { secondary control striving? }\end{array}$ \\
\hline $\begin{array}{l}\text { (1.4) } \\
\text { Other/Related } \\
\text { Constructs }\end{array}$ & & & & \\
\hline $\begin{array}{l}(1.4 .1) \\
\text { Causality } \\
\text { Orientation } \\
\text { (Self- } \\
\text { Determination) }\end{array}$ & $\begin{array}{l}\text { What initiates and regulates } \\
\text { my behavior? }\end{array}$ & $\begin{array}{l}\text { "General, motivational } \\
\text { orientations...usefully } \\
\text { characterized in terms of } \\
\text { people's (explicit or implicit) } \\
\text { understanding of the nature of } \\
\text { causation of behavior" (Deci } \\
\text { \& Ryan, 1985a, p. 111) }\end{array}$ & Deci \& Ryan (1985) & \\
\hline
\end{tabular}




\begin{tabular}{|c|c|c|c|c|}
\hline Variable & Key Question & Definition & $\begin{array}{l}\text { Theories and/or Key } \\
\text { Citation(s) }\end{array}$ & $\begin{array}{l}\text { Applications to Age and Aging at } \\
\text { Work }\end{array}$ \\
\hline $\begin{array}{l}\text { (1.4.2) Learned } \\
\text { Helplessness }\end{array}$ & $\begin{array}{l}\text { Why try when, based on } \\
\text { past experience and other } \\
\text { factors, I don't believe I can } \\
\text { accomplish my goal(s)? }\end{array}$ & $\begin{array}{l}\text { A sense of powerlessness and } \\
\text { subsequent goal } \\
\text { disengagement when an } \\
\text { individual who has available } \\
\text { goal-relevant means does not } \\
\text { perceive control over their } \\
\text { situation }\end{array}$ & $\begin{array}{l}\text { Abramson, Seligman, \& } \\
\text { Teasdale (1978); Roth } \\
\text { (1980); Seligman (1975) }\end{array}$ & \\
\hline $\begin{array}{l}\text { (1.4.3) } \\
\text { Environmental } \\
\text { Mastery/Auton } \\
\text { omy }\end{array}$ & $\begin{array}{l}\text { Do I manage my } \\
\text { environment and take } \\
\text { advantage of opportunities } \\
\text { presented to me? Do I act } \\
\text { independently from social } \\
\text { pressures? }\end{array}$ & $\begin{array}{l}\text { "Self-determining and } \\
\text { independent; able to resist } \\
\text { social pressures to think and } \\
\text { act in certain ways"; "has } \\
\text { sense of mastery and } \\
\text { competence in managing the } \\
\text { environment...makes effective } \\
\text { use of surrounding } \\
\text { opportunities" (Ryff, 1995, p. } \\
\text { 101) }\end{array}$ & Ryff (1995) & \\
\hline $\begin{array}{l}(1.4 .4) \\
\text { Predictability }\end{array}$ & $\begin{array}{l}\text { Can I anticipate events in a } \\
\text { given context? }\end{array}$ & $\begin{array}{l}\text { The ability to "predict the } \\
\text { frequency, timing, and } \\
\text { duration of events in } \\
\text { the...environment" (Tetrick \& } \\
\text { LaRocco, 1987, p. 1987) }\end{array}$ & Sutton \& Kahn (1986) & \\
\hline
\end{tabular}

Note. Numbering denotes control categories and types represented in each area of the review and framework, and it corresponds to numbering in Figure 1 and the manuscript. 
Table 2

Recommended Uses of and Considerations for the Lifespan Control Framework

\begin{tabular}{|c|c|c|c|}
\hline Recommendation & Rationale & Specific Applications & Example Use \\
\hline $\begin{array}{l}\text { Draw on foundational theory } \\
\text { for each category and form of } \\
\text { control when designing studies } \\
\text { and hypotheses }\end{array}$ & $\begin{array}{l}\text { Control-relevant theory is } \\
\text { abundant but infrequently or } \\
\text { incompletely used in current } \\
\text { work and aging studies with } \\
\text { control }\end{array}$ & $\begin{array}{l}\text { Specification of age-based } \\
\text { contingencies in hypotheses } \\
\text { Intentional choice of study } \\
\text { design, including time lags as } \\
\text { relevant, to align with } \\
\text { constructs and phenomena }\end{array}$ & $\begin{array}{l}\text { Identifying to whom, where, } \\
\text { and when theories were } \\
\text { intended to apply and what they } \\
\text { were intended to explain (e.g., } \\
\text { social learning theory and } \\
\text { studying perceived locus of } \\
\text { control) }\end{array}$ \\
\hline
\end{tabular}

Better measures of and measurement approaches for studying control phenomena at different levels Consider central control, aging, Subtle but important Adoption of consistent control and work issues and questions differences exist across the terminology when identifying and selecting various forms of control included in the aging and work Concerted efforts to describe constructs literature and justify what type(s) of control are being studied

Using constructs in line with their central control question and related aging and work issue (e.g., measuring multiple expectancies in studies of aging workers' motivation and multigoal systems)

Question control-based assumptions when reading, reviewing, interpreting data, and beyond

The ubiquity and legacy of
"control" in the literature is a
double-edged sword, and
control definitions,
propositions, and mechanisms
can be misrepresented in the
work and aging literature as a
result
Control forms do not exist in
isolation, and more research is
needed considering how they
interact with each other, age,
and work

Approach studies of control
with a holistic and integrative
spirit
can be misrepresented in the

\section{Maintenance of healthy} skepticism and vigilance to promote accuracy and innovation in the literature
Examining the construct validity and incremental contributions of purportedly novel measures of control (e.g., "new" forms of job control) control definitions,

$\begin{array}{ll}\text { Control forms do not exist in } & \text { Include multiple (but not all) } \\ \text { isolation, and more research is } & \text { control phenomena in work as } \\ \text { needed considering how they } & \text { appropriate }\end{array}$

Considering "actual,"

perceived, and enacted control

(e.g., discussing objective, perceptual, and self-regulated aspects of age-related changes) 
Table 3

Proposed Research Agenda for Age, Control, and Work

\section{Research Area \\ Temporal properties and effects} of control

\section{Example Research Questions}

How do "actual," perceived, and enacted control develop, change, or remain stable over time?

What are the trajectories and relative contributions of different forms of control to functioning over time, or at specific developmental junctures or life events?

How does control intersect with the aging process?

\section{Potential Research Designs}

Concurrent and longitudinal studies of multiple forms of control (i.e., charting control forms over the course of months and years) with age-diverse and representative samples

\section{Anticipated Contribution}

Nuanced understanding of the interplay between development and control (including the benefits of various forms of control), and their implications for workers at facing different life and career stages or events
Different "stages" of control experiences and control attributions

\author{
What causes control attributions \\ (e.g., about to specific control \\ experiences) to vary or stay the \\ same, and when are these \\ different attributions \\ (mal)adaptive? \\ How do past, present, and \\ prospective attributions of \\ control shape control striving \\ and functioning?
}

Are there quantifiable betweenand within-person differences in patterns of control attributions?

\section{Daily diary studies of control} attributions

Experimental or policy-capturing paradigms to simulate control experiences

Qualitative studies to document control narratives
Knowledge of the malleability of control perceptions and their role in life stories, sense-making, and decision making

Evidence for the distinctions and/or overlaps between control predictions, attributions, and appraisals 


\begin{tabular}{|c|c|c|c|}
\hline Research Area & Example Research Questions & Potential Research Designs & Anticipated Contribution \\
\hline $\begin{array}{l}\text { Cross-domain and -construct } \\
\text { control interactions }\end{array}$ & $\begin{array}{l}\text { How do control beliefs differ } \\
\text { across life domains? } \\
\text { What are the implications of } \\
\text { different forms of control (mis)fit } \\
\text { or incongruence within or across } \\
\text { areas of life? } \\
\text { What are the effects of social } \\
\text { partners and/or identities on } \\
\text { control needs, interactions, and } \\
\text { trade-offs? }\end{array}$ & $\begin{array}{l}\text { Fit-based assessments of different } \\
\text { forms of control in work, home, } \\
\text { leisure as well as different aspects } \\
\text { of life (e.g., health, finances, } \\
\text { community acceptance) } \\
\text { Relational, dyadic, or social } \\
\text { network data collections to capture } \\
\text { individuals' control contexts } \\
\text { Multidisciplinary collaboration } \\
\text { (e.g., sociology) to document life } \\
\text { course data }\end{array}$ & $\begin{array}{l}\text { Understanding of how } \\
\text { individual's levels of control are } \\
\text { influenced by and have influence } \\
\text { in multiperson and multidomain } \\
\text { life systems }\end{array}$ \\
\hline $\begin{array}{l}\text { Control experiences and forces } \\
\text { across levels }\end{array}$ & $\begin{array}{l}\text { How are different forms and } \\
\text { systems of organizational control } \\
\text { (e.g., monitoring, coordination; } \\
\text { formal, informal) experienced by } \\
\text { individuals? } \\
\text { What are the effects of different } \\
\text { levels of control, and what forces } \\
\text { determine where control most } \\
\text { effectively resides? }\end{array}$ & $\begin{array}{l}\text { Multilevel and multisource data } \\
\text { collection paradigms (e.g., archival } \\
\text { company records, occupation-level } \\
\text { data, job or task analyses, } \\
\text { managerial or other-reports) to } \\
\text { complement self-reported } \\
\text { experiences } \\
\text { Intervention studies with } \\
\text { appropriate randomization, } \\
\text { controls, and ethical considerations }\end{array}$ & $\begin{array}{l}\text { Evidence regarding the impact of } \\
\text { control-related policies and } \\
\text { practices on the aging workforce }\end{array}$ \\
\hline $\begin{array}{l}\text { Cultural and sociopolitical } \\
\text { components of control }\end{array}$ & $\begin{array}{l}\text { How do geographic, cultural, and } \\
\text { ideological forces influence the } \\
\text { benefits or drawbacks of } \\
\text { different forms of control? } \\
\text { In what ways to individuals' } \\
\text { needs for various forms of } \\
\text { control differ based on cultural } \\
\text { or other significant contexts? }\end{array}$ & $\begin{array}{l}\text { Multinational and geographically } \\
\text { diverse survey-based control } \\
\text { studies (e.g., control orientation, } \\
\text { preferences, desirability) }\end{array}$ & $\begin{array}{l}\text { Knowledge of the diversity and } \\
\text { pluralism inherent to aspects of } \\
\text { control, particularly as they } \\
\text { relate to aging and work amidst } \\
\text { globalization }\end{array}$ \\
\hline
\end{tabular}


Figure 1

Visual Representation of Lifespan Control Framework

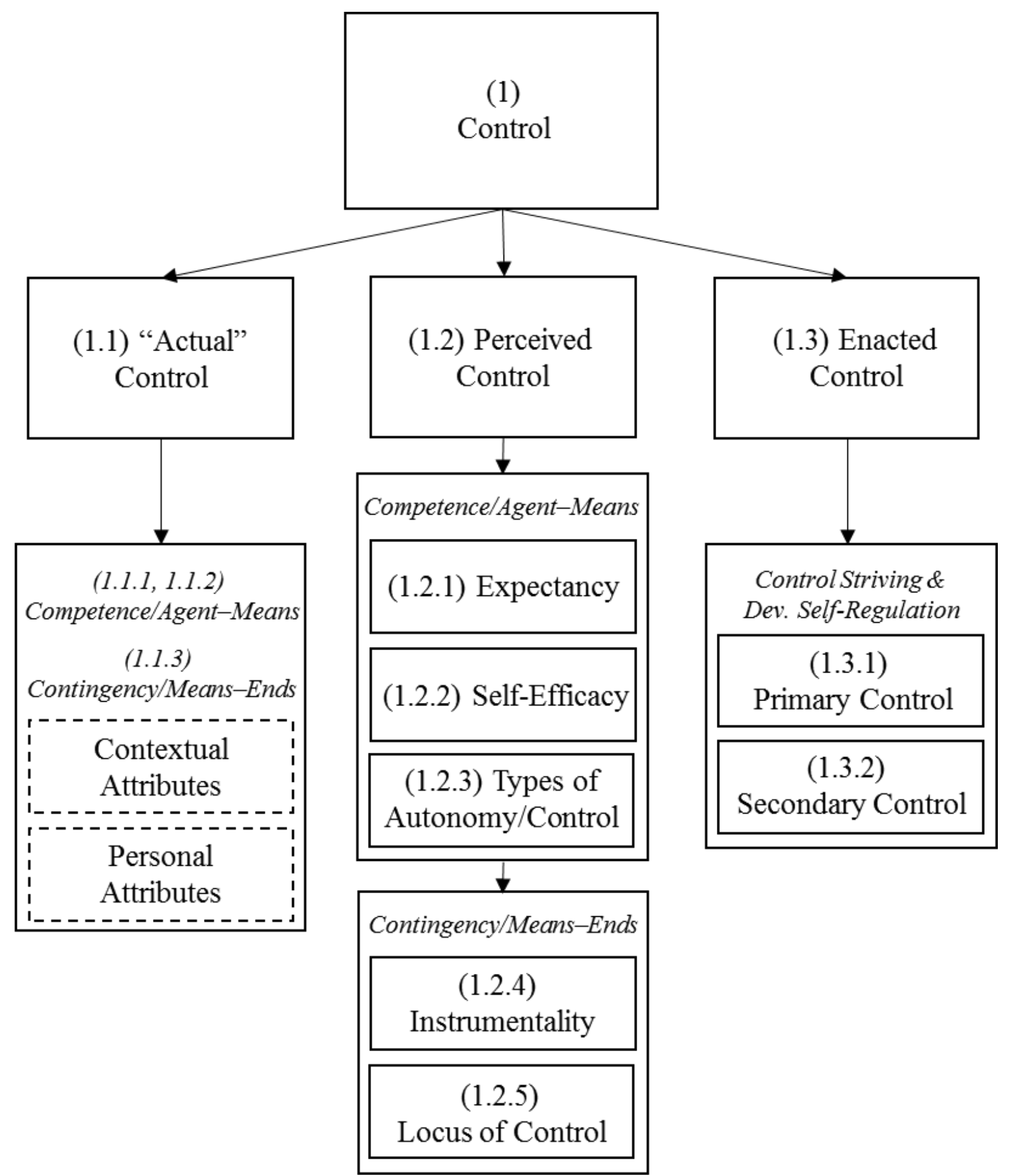

Note. Numbering denotes control categories and types represented in each area of the review and framework, and it corresponds to numbering in Table 1 and the manuscript. 